\title{
Distributed acoustic sensing as a tool for subsurface mapping and seismic event monitoring: a proof of concept
}

\author{
Nicola Piana Agostinetti ${ }^{1,2}$, Alberto Villa ${ }^{1}$, and Gilberto Saccorotti ${ }^{3}$ \\ ${ }^{1}$ DISAT, Universitá di Milano Bicocca, Piazza della Scienza 4, 20126 Milan, Italy \\ ${ }^{2}$ Department of Geology, University of Vienna, Vienna, Austria \\ ${ }^{3}$ Instituto Nazionale di Geofisica e Vulcanologia, Via Cesare Battisti 53, 56125 Pisa, Italy
}

Correspondence: Nicola Piana Agostinetti (nicola.pianaagostinetti@unimib.it)

Received: 2 April 2021 - Discussion started: 15 April 2021

Revised: 26 January 2022 - Accepted: 27 January 2022 - Published: 3 March 2022

\begin{abstract}
We use PoroTomo experimental data to compare the performance of distributed acoustic sensing (DAS) and geophone observations in retrieving data to execute standard subsurface mapping and seismic monitoring activities. The PoroTomo experiment consists of two "seismic systems": (a) a $8.6 \mathrm{~km}$ long optical fibre cable deployed across the Brady geothermal field and covering an area of $1.5 \times 0.5 \mathrm{~km}$ with $100 \mathrm{~m}$ long segments and (b) a co-located array of 238 geophones with an average spacing of $60 \mathrm{~m}$. The PoroTomo experiment recorded continuous seismic data between 10 and 25 March 2016. During this period, a $M_{1} 4.3$ regional event occurred in the southeast, about $150 \mathrm{~km}$ away from the geothermal field, together with several microseismic local events related to the geothermal activity. The seismic waves generated from such seismic events have been used as input data in this study to tackle similarities and differences between DAS and geophone recordings of such wavefronts.

To assess the quality of data for subsurface mapping tasks, we measure the propagation of the $\mathrm{P}$ wave generated by the regional event across the geothermal field in both seismic systems in term of relative time delays, for a number of configurations and segments. Additionally, we analyse and compare the amplitude and the signal-to-noise ratio (SNR) of the $\mathrm{P}$ wave in the two systems at high resolution. For testing the potential of DAS data in seismic event locations, we first perform an analysis of the geophone data to retrieve a reference location of a microseismic event, based on expert opinion. Then, we a adopt different workflow for the automatic location of the same microseismic event using DAS data. To assess the quality of the data for tasks related to monitoring distant events, we retrieve both the propagation direction and
\end{abstract}

apparent velocity of the wave field generated by the $M_{1} 4.3$ regional event, using a standard plane-wave-fitting approach applied to DAS data.

Our results indicate that (1) at a local scale, the seismic P-wave propagation (i.e. time delays) and their characteristics (i.e. SNR and amplitude) along a single cable segment are robustly consistent with recordings from co-located geophones (delay times $\delta t \sim 0.3$ over $400 \mathrm{~m}$ for both seismic systems); (2) the DAS and nodal arrays are in mutual agreement when it comes to site amplifications, but it is not immediately clear which geological features are responsible for these amplifications. DAS could therefore hold potential for detailed mapping of shallow subsurface heterogeneities, but with the currently available information of the Brady Hot Springs subsurface geology, this potential cannot be quantitatively verified; (3) the interpretation of seismic wave propagation across multiple separated segments is less clear due to the heavy contamination of scattering sources and local velocity heterogeneities; nonetheless, results from the planewave-fitting approach still indicate the possibility for a consistent detection and location of the distant event; (4) automatic monitoring of microseismicity can be performed with DAS recordings with results comparable to manual analysis of geophone recordings in the case of events within or close to the DAS system (i.e. maximum horizontal error on event location around $70 \mathrm{~m}$ for both geophone and DAS data); and (5) DAS data preconditioning (e.g. temporal subsampling and channel stacking) and dedicated processing techniques are strictly necessary for making seismic monitoring procedures feasible and trustable. 


\section{Introduction}

Distributed acoustic sensing (DAS) is a novel technology that records ground vibrations necessary for seismological investigations of the shallow crust (You, 2010; Jousset et al., 2018). DAS technology can be used to record vibrations of a optical fibre cable in terms of the temporal derivative of the strain along the cable direction (Wang et al., 2018). DAS recordings of ground motion along a fibre cable can be obtained at unprecedented high resolution (less than $1 \mathrm{~m}$, if necessary) without the need for deploying tonnes of instruments on the ground (Henninges et al., 2021). Moreover, DAS recordings can be obtained for Earth's regions which could be unfeasible to reach with standard seismological instruments (e.g. the ocean floor, Lindsey et al., 2019). Highresolution seismic recordings are necessary for both the characterisation of next-generation georesources (e.g. enhanced geothermal system (EGS) or reservoirs for $\mathrm{CO}_{2}$ storage), and the monitoring of georesource exploitation (e.g. monitoring of induced seismicity in geothermal wells, Li and Zhan, 2018).

The potential of DAS recordings to be used as "standard" seismic signals has been investigated in previous works (e.g. Yu et al., 2019). In general, DAS recordings can be used for locating off-shore seismic events (Sladen et al., 2019) and reconstructing geological structures in the shallow crust (e.g. Ajo-Franklin et al., 2019). However, some concerns have been raised. For example, van den Ende and Ampuero (2021) highlights the difficulties in using DAS recordings with beam-forming techniques for locating events at large epicentral ranges (i.e. using the fibre as a standard seismic array). Moreover, partial coupling of the cable to the ground, especially for dark fibre, could be a challenge in harsh environments (e.g. Sladen et al., 2019).

The PoroTomo experiment investigated the Brady geothermal field with both conventional seismic instruments (238 short-period three-component seismometers) and $8.6 \mathrm{~km}$ of optical fibre cable (Feigl and PoroTomo Team, 2017). PoroTomo seismic data and DAS recordings have been previously analysed in numerous other studies (Zeng et al., 2017; Parker et al., 2018; Wang et al., 2018; Jreij et al., 2021). In particular, Wang et al. (2018) strictly compares the signal recorded from DAS channels and co-located seismometers for a $M_{1} 4.3$ regional event occurred near Hawthorne (about $150 \mathrm{~km}$ southsoutheast from the test site). The authors tested different theoretical approaches, like matching the difference of two geophone waveforms with the amplitudes of the sum of the DAS channels in between, obtaining promising results. From application of template matching to DAS recordings, Li and Zhan (2018) detected microseismic activity at a signal-tonoise ratio (SNR) below 1, which was then compared to the pumping history of the geothermal field (Cardiff et al., 2018).
In this study, we move a step forward and test the potential of DAS recordings to produce data for specific tasks, namely "subsurface mapping" and "detection and location of seismicity". For "subsurface mapping", we mean the definition of spatial variations of elastic properties in the subsurface at high resolution. With "seismic event detection and location", we have in mind those activities adopted in real-time monitoring procedures. We build on the previous studies and we assume that DAS recordings are coherent to standard seismographic recordings, in the sense that the fibre cable is able to sense elastic waves traversing the rocks where the cable is deployed. From this starting point, we investigate (1) how standard observables used in subsurface mapping (and their spatial variation across the geothermal field) can be extracted from DAS recordings; and (2) how DAS recordings perform in the automatic detection and location of earthquakes at two different scales of epicentral distance, local and regional. In both cases, we strictly compare the observations obtained using DAS recordings, with similar analyses performed on colocated seismometers. We anticipate here that the main differences of the results obtained with DAS recordings, with respect to standard seismology, are (1) the necessity for treating a huge amount of data; and (2) the availability of horizontal recordings only, which requires particular care by the time of interpreting results obtained from standard seismic analysis tools.

\subsection{Geological background and the PoroTomo experiment}

The Brady geothermal system is located in the Hot Springs Mountains, northwestern Nevada, USA. The geothermal reservoir lies within layered Tertiary volcanic rocks covered by a sedimentary layer of variable thickness (Jolie et al., 2015). The bottom of the geothermal reservoir is constituted by a Mesozoic metamorphic and plutonic crystalline basement, which is found at depths between 600 and $1500 \mathrm{~m}$ below the surface.

The main structural feature of the area is the Brady fault zone, a fault system extending for some $10 \mathrm{~km}$ with a dominant NNE strike and steeply dipping to the NW. The geothermal system is strictly related to the presence of those steeply dipping normal faults, where dilatation at depth promotes the fluids' circulation (Faulds et al., 2006). The Brady geothermal system is the only one in the area that displays surface geothermal phenomena, for about $4 \mathrm{~km}$ along the Brady fault zone. In the area of interest, such geothermal phenomena (e.g. fumarole warm grounds and mud volcanoes) are found, mainly distributed in between the surface expression of two branches of the Brady fault (Fig. 1). The Brady geothermal field is classified as a high-enthalpy geothermal resource, reaching a temperature close to $180^{\circ} \mathrm{C}$ (Shevenell and De Rocher, 2005).

The PoroTomo experiment (Feigl and Parker, 2019) covers the northwestern part of the Brady geothermal field where 


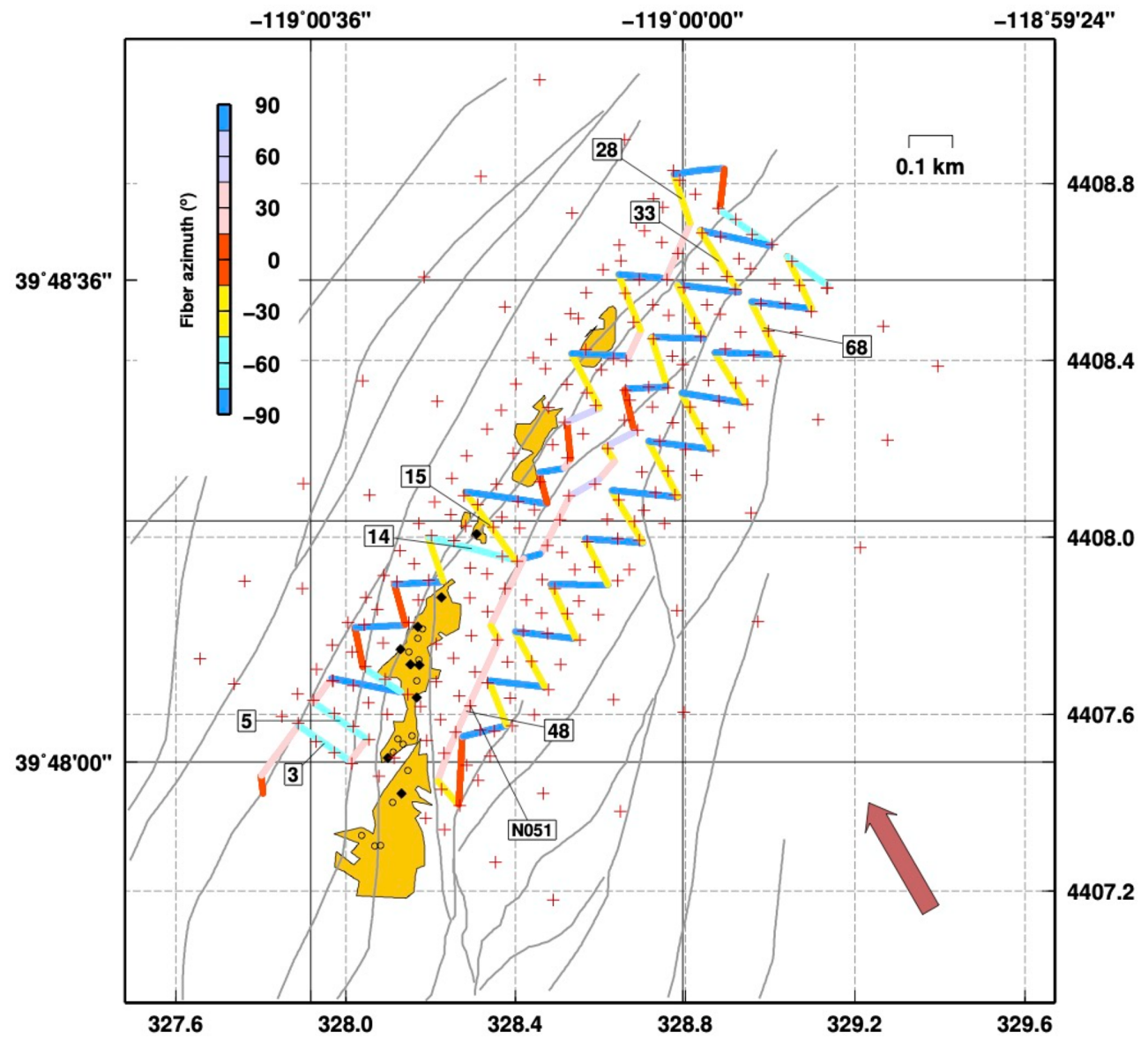

Figure 1. PoroTomo experiment map: fibre cable used for DAS (coloured line; colours indicate average azimuth of the segments), numbers indicate segments described in the text; nodal stations; faults (grey lines), warm ground (yellow areas); fumaroles (black diamonds) and mud volcanoes (open diamonds). A red arrow indicates the direction of an incoming $\mathrm{P}$ wave for the $M_{\mathrm{W}} 4.3$ Hawthorne earthquake.

subsidence has been observed in the past (Ali et al., 2016). In the PoroTomo area, close to the locations of several injection wells, water circulation models suggest that almost horizontal water flow at shallow depth should occur from the northwest toward the southern portion of the geothermal field. The PoroTomo experiment tested different technologies and different tools for the analysis of the ground deformation of the Brady geothermal field during a predefined sequence of human activities at the geothermal wells (e.g. repeated injections). All geophysical data recorded and collected during PoroTomo experiment can be found on the Geothermal Data Repository (GDR) repository (Feigl and PoroTomo Team, 2016), together with information on the geothermal operations. Among others, data from the PoroTomo experiment have been used for comparison of catalogs of microseismicity and pumping records on a daily basis (Cardiff et al., 2018), detection of microseismic events through template matching applied to DAS data ( $\mathrm{Li}$ and Zhan, 2018), active seismic tomography (Parker et al., 2018), comparison of DAS and geophone data for regional seismic waves (Wang et al., 2018) and evaluation of beam-forming potential in DAS data (van den Ende and Ampuero, 2021).

\section{Data and methods}

We make use of DAS recordings acquired during March 2016 in the framework of the PoroTomo experiment (Feigl and PoroTomo Team, 2017). The optical fibre cable was deployed with a zig-zag geometry composed of 71 contiguous segments; on average, the length of individual segments was on the order of $150 \mathrm{~m}$. Relevant segments used in the next sections are numbered in Fig. 1. Acquisition gauge length is fixed to $10 \mathrm{~m}$, with channel sampling every $1 \mathrm{~m}$ (Wang et al., 2018)

\subsection{Subsurface mapping}

For the subsurface mapping tasks, described in Sect. 3.1, we use one channel every gauge length $(10 \mathrm{~m})$ and discard the channels too close $(10 \mathrm{~m})$ to the bending point of the cable (as done in Wang et al., 2018). Given the segment 

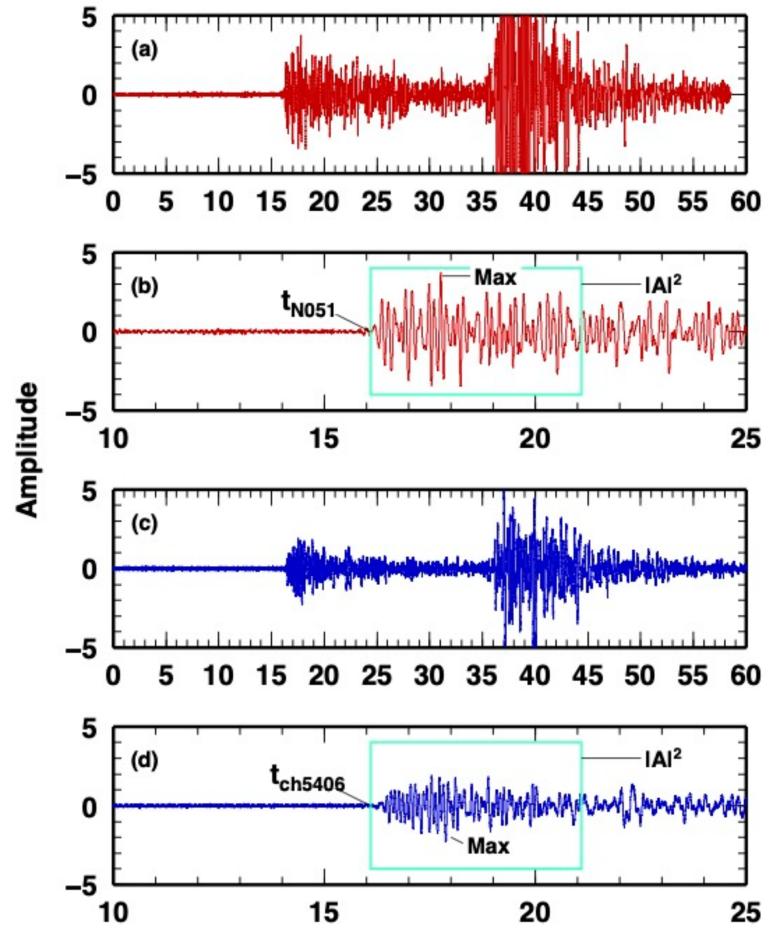

Time (s)

Figure 2. Waveforms generated from the $M_{m}$ athrmw 4.3 Hawthorne earthquake, with a zoom on $\mathrm{P}$ wave with the quantities analysed in the study: P-wave arrival time, MAX amp, energy in the $\mathrm{P}$ window (for computing SNR). Node 51: (a-b) closest DAS channel to node 51 (channel 5406) (c-d).

length and the gauge length, we obtain about 10-15 independent acoustic records for each segment. The acoustic signals are recorded at $1000 \mathrm{sps}$. DAS data are organised in $30 \mathrm{~s}$ long HDF5 files, about one $1 \mathrm{~GB}$ for each file. In parallel, we also downloaded and analysed data recorded by a co-located array of 238 nodal geophones ("Fairfield Nodal ZLand" short-period three-component seismometers, with a peak frequency of $4.5 \mathrm{~Hz}$, called "nodes" hereinafter). Nodes had been deployed as close as possible to the fibre, allowing a detailed comparison of the signal recorded by the DAS and nodes systems.

We make use of the waveforms relative to the $M_{1} 4.3$ Hawthorne event. In this case, the analysis is limited to Pwave arrival. The $\mathrm{P}$ wave can be clearly seen in both DAS and nodes recording (Fig. 2). Here, we filter the waveforms between 0.5 and $2 \mathrm{~Hz}$, enhancing the earthquake signal. DAS recordings are downsampled to $500 \mathrm{sps}$, to be consistent with nodes recordings. To compare nodes to DAS recordings, horizontal components of the nodes are rotated to match the azimuth of the closest segment of fibre cable (Fig. 1). All computations on nodal recording are operated on the rotated seismograms, if not specified.
The analysis of the $M_{1} 4.3$ event consists in the automatic determination of the relative P-wave arrival times for each segment of fibre cable and for all co-located nodes. The P-wave time delays are computed following the approach described in VanDecar and Crosson (1990) and in Piana Agostinetti and Martini (2019). For each of the three experiments (see Sect. 3.1), we compute the P-wave time delays for the selected DAS channels (one every $10 \mathrm{~m}$ ). Following VanDecar and Crosson (1990), we compute (1) the time delay between all couples of selected channels, cross correlating a $2 \mathrm{~s}$ long time window; (2) the absolute time delay $\delta t_{i}$ for the $i$ th selected channel under the condition of $\sum_{i} \delta t_{i}=0$; and finally (3) the uncertainty on the absolute time delay $\delta t_{i}$ following the Bayesian approach described in Piana Agostinetti and Martini (2019), where, for each couple of channels, a family of relative P-wave time delays is retrieved using a Markov chain Monte Carlo sampling, and posterior estimates of the standard deviations are obtained from this family. The same procedure is performed for the oriented horizontal recordings of the co-located nodes. After the definition of the time delays, we measure the SNR for each channel and each node, considering a $5 \mathrm{~s}$ long time window before and after the P-wave arrival (Fig. 2). On the same time window that contains the $\mathrm{P}$ wave, we also measure the maximum amplitude.

\subsection{Seismic event detection and location}

For the detection and location tasks, we consider two test cases of earthquakes recorded at regional and very local ranges. For the former case, we use the aforementioned Hawthorne earthquake. For the latter, we consider the list of micro-earthquakes obtained by Li and Zhan (2018) from template matching of five events catalogued by the Northern California Earthquake Data Center (UC Berkeley Seismological Laboratory, 2014).

\subsubsection{Local earthquakes}

DAS recordings of the local earthquakes are band-pass filtered over the $2-20 \mathrm{~Hz}$ frequency band, and resampled at $100 \mathrm{~Hz}$. A spatial subsampling is then performed by stacking groups of 11 adjacent channels within each segment, with a 30-channel step. The 10 channels before and after each corner are excluded. Resulting from this procedure is a virtual array whose total number of channels (239) is similar to that of the nodal array. For each stacked trace, we calculate a characteristic function given by the kurtosis (Langet et al., 2014) and use an Akaike information criterion (AIC) autopicker (Sleeman and van Eck, 1999) to automatically identify the onset time of these functions. Finally, we use the density-based spatial clustering of applications with noise (DBSCAN) algorithm (Ester et al., 1996) to discard the most 
obvious outliers. The same procedure is adopted for the automatic estimate of P-wave arrival times at the vertical components of the nodal array.

For each event, reference locations are obtained from inversion of manually picked $\mathrm{P}$ - and S-wave arrival times estimated at stations of the nodal array and, when available, from the UC Berkeley Seismological Laboratory (2014) catalogue. Hypocentral locations are retrieved using the probabilistic, non-linear approach coded into the NonLinLoc software package (Lomax et al., 2009); the likelihood function for source location is explored using the octet-tree sampling method.

\subsubsection{Regional earthquake}

For the Hawthorne earthquake, 2 min long DAS recordings are band-pass filtered over the $0.5-2 \mathrm{~Hz}$ frequency band, and resampled at $100 \mathrm{~Hz}$. Spatial subsampling is performed in a similar manner to what described above, but stacking over 51 adjacent channels with a 50-channel step, thus obtaining a virtual array of 102 elements. Delay times $\Delta T_{i j}, i \neq j$ between all the independent array channels are derived from the maxima $\mathrm{CC}^{\max }$ of the corresponding cross-correlation function. These differential times are used to derive the horizontal slowness vector following the plane-wave-fitting (PWF) method (Del Pezzo and Giudicepietro, 2002)

$\Delta \boldsymbol{T}=\Delta \boldsymbol{x} \cdot \boldsymbol{s}$,

where the matrix $\Delta \boldsymbol{x}$ contains the differences between the $x$ (EW) and $y$ (NS) components of the array channel's coordinates, and $s$ is the horizontal slowness vector, from which we derive the propagation azimuth (measured clockwise from the $\mathrm{N}$ direction) and apparent velocity.

Equation (1) is solved using a weighted least-squares approach, with weights defined as

$w_{i j}=\frac{\mathrm{CC}_{i j}^{\max }}{1-\mathrm{CC}_{i 1}^{\max }}$,

so to emphasise the contribution of the most correlated channels. For the inversion, we considered only those channel pairs exhibiting a $\mathrm{CC}^{\max }$ larger than an arbitrary threshold, here set equal to 0.85 . The procedure is iterated over $4 \mathrm{~s}$ long time windows, sliding along the DAS recordings with $80 \%$ overlap. Slowness uncertainties, and corresponding errors in azimuth and ray parameter estimates, are derived assuming a constant error of twice the sampling interval (i.e. $0.02 \mathrm{~s}$ ).

\section{Results}

\subsection{Subsurface mapping}

Direct comparison of DAS and nodal recordings is not possible, due to the sensitivity of the two seismic systems to different geo-observables. Many different procedures have been developed to convert DAS recordings to nodal recordings, and vice versa (Wang et al., 2018, and references therein). Here, we do not aim to use the two systems together in the same analysis but to compare the performance of the two systems on the same analysis workflow. Thus, we do not transform one system into the other, but we use them separately. However, for only one case, we start our analysis reproducing the results obtained in Wang et al. (2018) for comparing the two systems using the amplitudes of the sum of several DAS strain-rate waveforms along a segment and the finite difference of two geophone waveforms at the two ends of the same segment. We use the DAS data recorded along segment 15 , where four nodes have been co-deployed (Fig. 3). This allows us to divide the segment 15 into three subsegments and analyse each subsegment as an independent set of information (i.e. only data from the four geophones have been used twice). We make use of the workflow of Wang et al. (2018, Fig. 9 and Eq. 5), composing a "representative DAS waveform" from the sum of one channel of DAS data every $10 \mathrm{~m}$ in between two geophones and comparing it to the "finitedifference nodal waveform" of the two geophone waveforms. Our results confirm the finding in Wang et al. (2018), where the authors indicate that the amplitudes recorded by the two systems are coherently correlated. We also observe, as found in Wang et al. (2018), a small absolute time delay between the two systems, that we correct cross correlating the "representative DAS waveform" with the finite-difference nodal waveform.

The propagation of the $\mathrm{P}$ wave generated by the $M_{1} 4.3$ event can be easily tracked across the PoroTomo investigated area using the vertical components of the geophones. Such analysis can be used as a reference of the general propagation direction and time delay. To get a first insight on the potential local anomalies in the P-wave propagation, we process vertical and north components of the nodes. In this case, we make use of the same tool (i.e. cross correlation of the waveforms following VanDecar and Crosson, 1990) without rotating the horizontal as described in the previous section. Vertical components of the nodes clearly display similar P-wave arrivals, and the cross-correlation procedure gives correlation coefficients as high as 0.96-0.99 on average (Fig. 4). Mapping the time delay obtained with the application of the VanDecar and Crosson (1990) s approach shows a south-southeast to north-northwest propagation as expected (Fig. 5a). On the contrary, repeating the same analysis for the north component of the nodes and mapping the results, we observe that the wave propagation is more complex showing, for example, an area in the centre of the nodal array, where strong negative time delays are observed (Fig. 5b). Those could be apparent anomalies given by local surface waves generated from interaction of the $\mathrm{P}$ wave with the local topography and erroneously cross correlated with the correct $P$ wave. Nevertheless, this result supports our workflow where DAS data need to be strictly compared to co-located, re-oriented nodal data; 

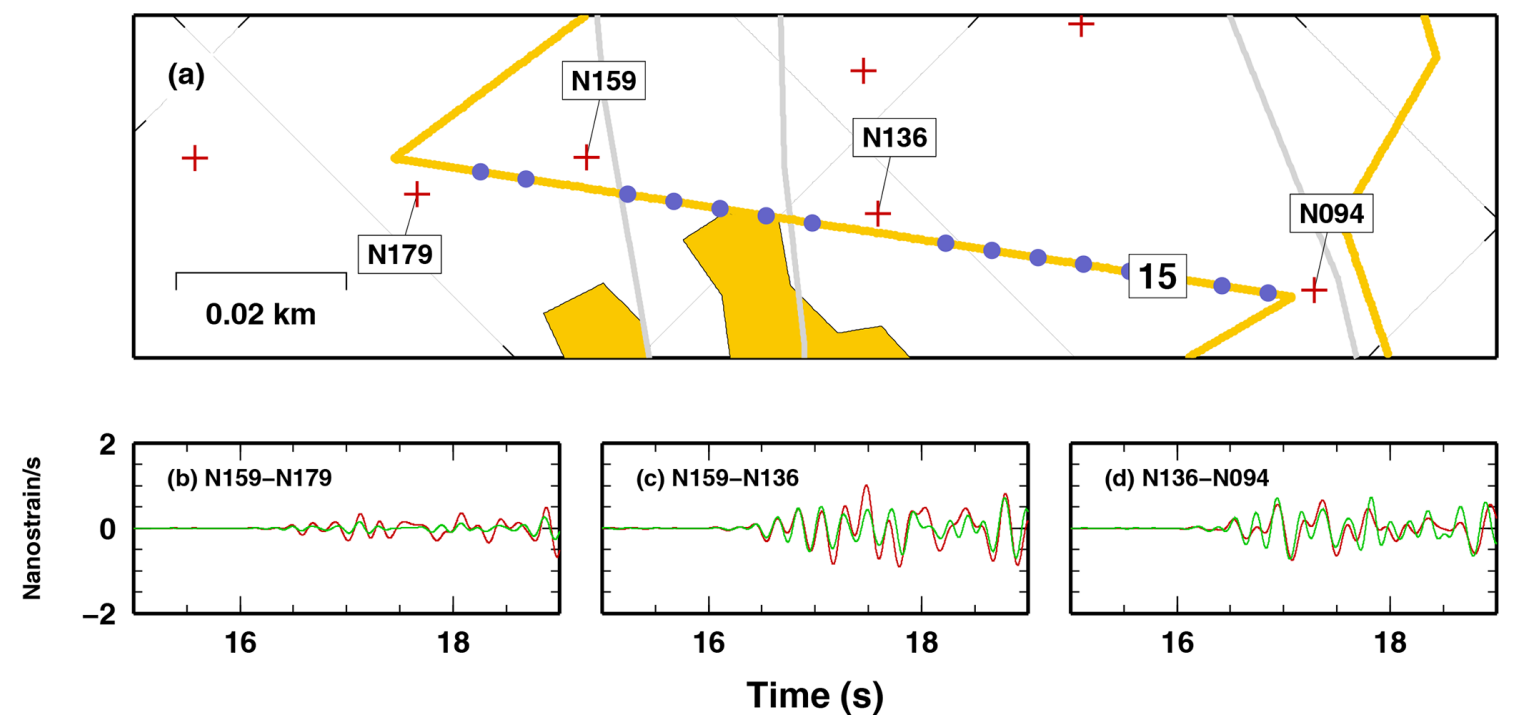

Figure 3. Comparison of DAS and NODAL recordings, following Wang et al. (2018) Eq. (5). (a) Map of DAS segment 15 and co-located nodes. P-wave arrival in the three subsegments as temporal derivative of strain, between (b) node 94 and node 136; (c) node 136 and node 159; (d) node 159 and node 179 .

i.e. nodal horizontal components need to be vector summed in the DAS direction.

We first present the analysis on the $\mathrm{P}$ wave recorded by the DAS system, considering DAS segment 48 . This segment is the longest one (about $350 \mathrm{~m}$ ), with seven geophones almost co-located along the cable (within $30 \mathrm{~m}$ ), and it gives us the possibility of following the $\mathrm{P}$ wave over a long distance (Fig. 7). P waves recorded along the cable are generally similar but not as much as on the vertical components of the nodal system, giving smaller cross-correlation coefficients (about 0.95 on the average, Fig. 6), with some waveforms displaying large pre-signal noise (channels 5534 and 5524 in Fig. 6a). Mapping the time delays and the other quantities for the two systems shows that the time delays are generally consistent, considering the computed uncertainties. Time delays decrease from 0.19 to $-0.05 \mathrm{~s}$ (with a minimum of $-0.10 \mathrm{~s}$ ) for the nodes and from 0.19 to $-0.15 \mathrm{~s}$ for the DAS data. In particular, only one geophone (N051) does not follow the uncertainties in time delay computed from the DAS recordings. However, such a geophone could have had issues (see also Appendix A). It is noteworthy that vertical components of the nodal system display a more limited decrease in Pwave delay time going from south to north, between 0.11 and $-0.04 \mathrm{~s}$, confirming that vertical and horizontal components give different measurements, as found above. Maximum amplitude in the two systems also displays similar spatial trends. More interestingly, SNR in the DAS system has a sudden drop at about $X=-100 \mathrm{~m}$ in our profile projection (Fig. 7d), where we also observe the nosiest waveforms (Fig. 6a), possibly indicating a partial failure in the cable coupling to the ground. However, such defect (if existent) does not bias the time-delay measurement.
We repeat the same experimental setting for three nearparallel and consecutive DAS segments: 28,33 and 68 . Those segments have almost the same azimuth of N30W, they are aligned but are not contiguous, and they cover a $500 \mathrm{~m}$ long profile. Nine geophones have been deployed close to such segments (Fig. 8). Also in this case, the spatial variations of time delay, SNR and maximum amplitude between the two systems is coherent. Time delays on the horizontal components of the nodal system display values between -0.05 and $0.15 \mathrm{~s}$, a larger value with respect to what we could expect from standard estimations (considering a $450 \mathrm{~m}$ long cable and an average apparent P-wave speed of $5 \mathrm{~km} \mathrm{~s}^{-1}$; van den Ende and Ampuero, 2021, consistent with beamforming analysis). SNR does not vary significantly, with a small decrease toward south. Maximum amplitude displays a sharp decrease from north to south in both systems in the first hundred metres. The two systems are not perfectly coherent, but one geophone out of three is far from the cable (about $50 \mathrm{~m}$ ). Time delay shows contrasting evidence in the two systems at the end of the profile toward the south, even considering the computed uncertainties. While the overall trends in the two system is coherent (i.e. largest values in the central portion of the profile and smallest at the two ends), a $60 \mathrm{~m}$ long cable section of segment 68 shows time delays as small as $-0.20 \mathrm{~s}$, which is not found in the geophone data. A close inspection of the waveforms (Fig. 8e-f) reveals the presence of possibly scattered waves in DAS recordings at channel 8179 (i.e. strong differences from channel 8199, not found in the nodal system, where differences in the recordings of co-located nodes, N046 and N069, are minimal).

To test the possibility of appreciating 3-D features, we apply our workflow to two parallel but not aligned segments, 


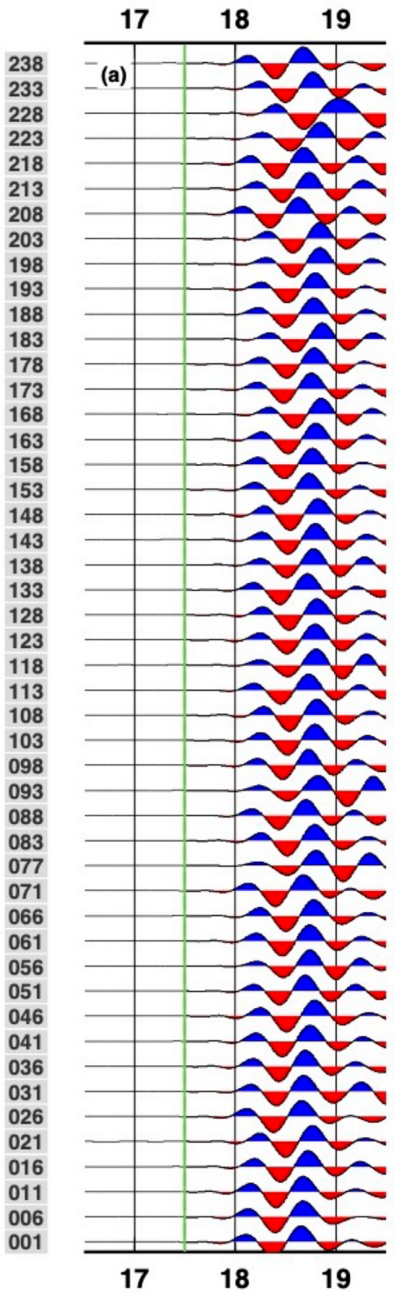

Relative time (s)

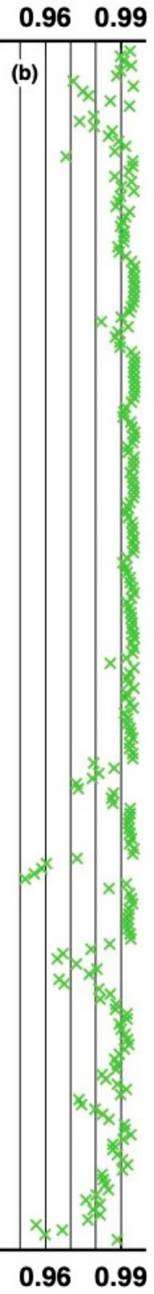

Mean C

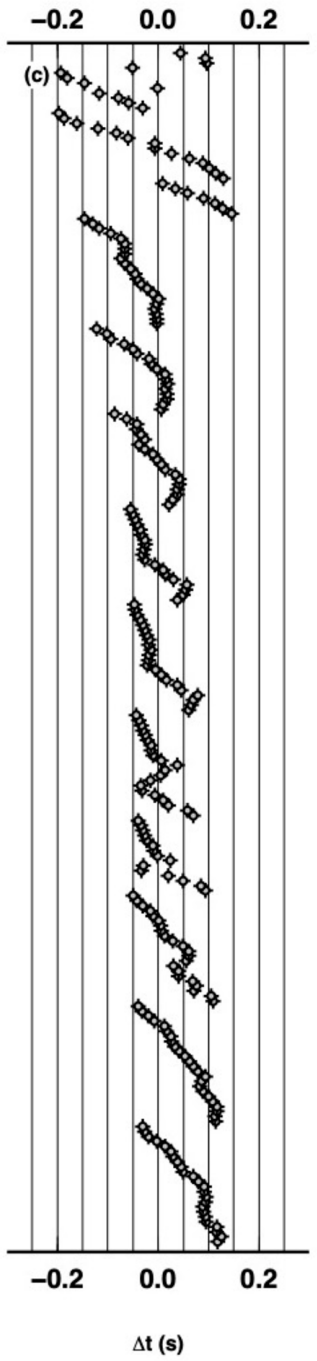

Relative time (s)

Figure 4. Example of analysis for computing P-wave time delays using VanDecar and Crosson (1990)'s approach applied to vertical recordings of nodal seismometers. (a) Original waveforms filtered between $0.5-2 \mathrm{~Hz}$ showing P-wave arrivals. (b) Average cross-correlation value for each station cross correlated to all others. (c) Relative P-wave time delays. (d) Aligned P-wave arrival using time delays in panel (c). Stations are ordered by station names. Only one in every five stations is shown in panels (a) and (d) for clarity.

3 and 5 that run along the longer side of a rectangular area of about $150 \times 70 \mathrm{~m}$. Eight geophones are deployed along the two segments (four geophones per segment, Fig. 9). The results indicate that both time delays and maximum amplitude display the same spatial variation. In particular, time delay ranges between -0.12 and $0.12 \mathrm{~s}$ for both systems and indicate an unexpected east-to-west propagation. Amplitude variation are coherent in both system, increasing toward the west. Both P-wave delay times and amplitude spatial variation correlate with the $\mathrm{P}$-wave velocity gradient found in Parker et al. (2018). In such a velocity model, north-southoriented velocity anomaly is found at shallow depth (Fig. 8a, b in Parker et al., 2018), potentially related to the local fault system.
In this case, we notice that channels close to the end of the segments are generally different from the closest one. We suggest that the practise of removing the channels closer to the bending point of the fibre should be revised increasing the lag distance, now $10 \mathrm{~m}$ (a lag of 15 or $20 \mathrm{~m}$ could work fine).

Finally, we analysed separately all segments between 1 and 27 , covering the northwestern side of the PoroTomo experiment, where most of the geothermal phenomena are found bounded by two faults mapped at the surface (i.e. fumaroles and warm ground, Fig. 10). The variations of the maximum amplitude show that the highest values, i.e. where maximum amplitude goes beyond the threshold of 0.1 , are found in the only two places where the fibre cable crosses the geothermal active area (i.e. near the northernmost fu- 


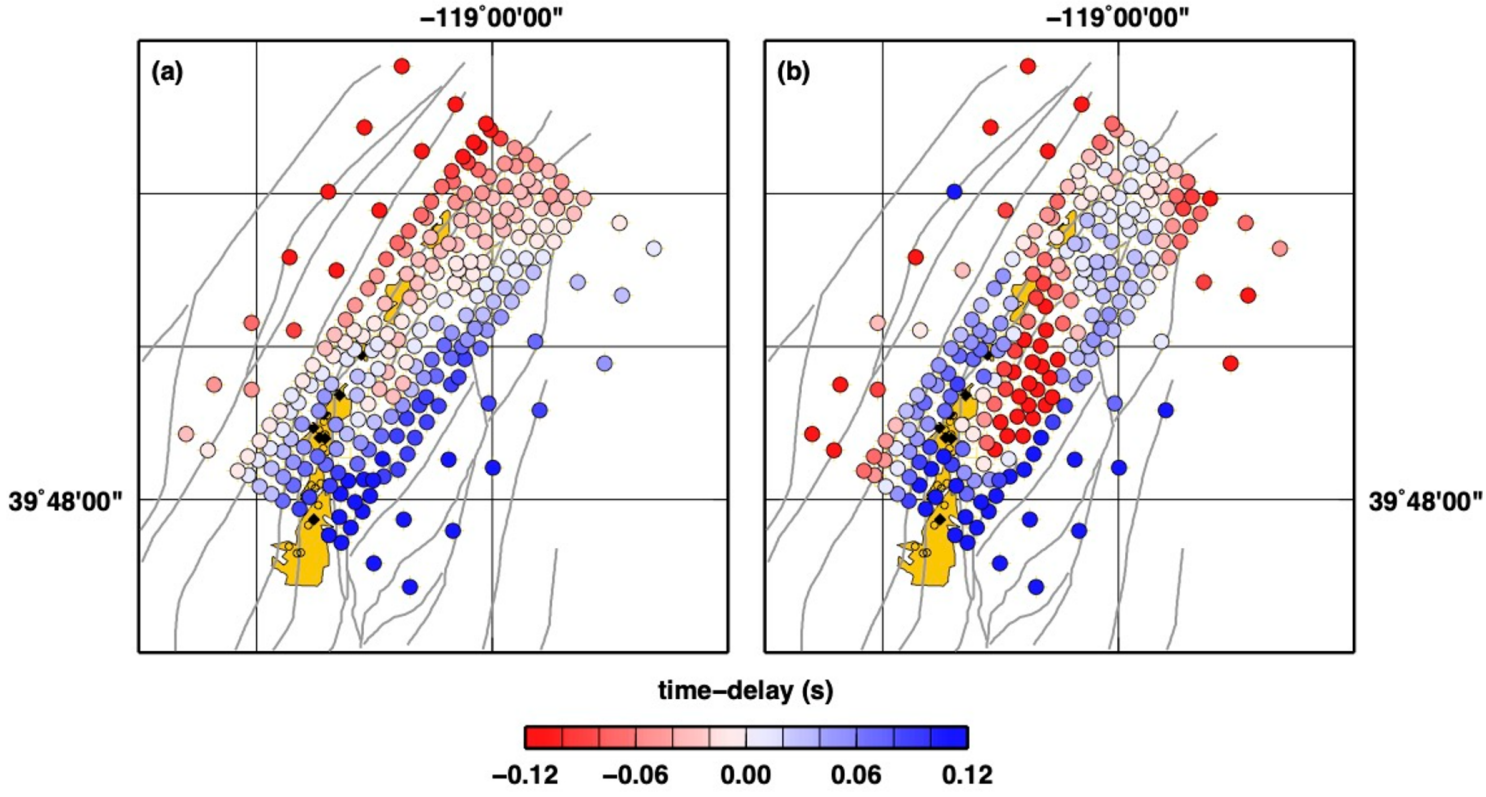

Figure 5. Maps of P-wave time delay from correlation of recordings by nodal stations. Waveforms have been filtered to $0.5-2.0 \mathrm{~Hz}$ : (a) vertical components; (b) north components.

maroles and where warm ground is mapped) roughly traversing the two bounding faults. Given the nature of the geothermal phenomena, we suggest that amplitude variations in this case could be related to local site effects associated with the development of the underground fracture network. Comparison with available velocity models show controversial details. On one hand, the area with the highest amplitude perfectly correlates with a very well-defined volume showing very low $V_{\mathrm{P}}$ values with respect to the surrounding rocks. Conversely, the second interesting area, more to the north, does not show any relevant velocity anomaly. In such area, where all the injection wells are located, we were expecting a well-developed fracture network and thus a low-velocity rock volume.

\subsection{Seismic event detection and location}

\subsubsection{Local earthquake}

For comparing the performances of the nodal and DAS deployment toward the automatic location of microearthquakes at short distance ranges, we focus on an earthquake reported in the template-matching earthquake catalogue of $\mathrm{Li}$ and Zhan (2018), with detection time on 14 March 2016 at 10:42:07 UTC. Following a preliminary inspection of arrival times, that event appeared to be located in close proximity to the DAS and nodal deployments, in turn exhibiting good visibility of both waveforms and cross correlations (see also the supplement of Li and Zhan, 2018).

For deriving a reference location, precise $\mathrm{P}$ - and $\mathrm{S}$-wave arrival times are estimated manually at 75 vertical and 48 horizontal channels of the nodal array. P-wave theoretical travel times are calculated in a 1-D gradient velocity model, obtained after averaging the 3-D velocity structure reported by the University of Wisconsin (2015) (see the Supplement, Fig. S1). The corresponding S-wave travel times are derived considering a ratio between $\mathrm{P}$ - and $\mathrm{S}$-wave velocities $\left(V_{\mathrm{P}} / V_{\mathrm{S}}\right)$ equal to 2.6 , as indicated by the modified Wadati diagram (Fig. S2 in the Supplement).

Figure 11 illustrates the comparison between the reference location obtained from manual picking of nodal data (Fig. 11a), and those derived from the automatic processing of both the DAS and nodal arrays (Fig. 11bc). The location from the $\mathrm{P}$ - and $\mathrm{S}$-wave inversion indicates a wellconstrained source volume located at the centre of the SW side of the deployment, at a depth of $460[ \pm 49] \mathrm{m}$ beneath the surface (Fig. 11a). Horizontal uncertainties are on the order of 63 and $75 \mathrm{~m}$ for the EW and NS coordinates, respectively; the root mean square (rms) of residuals is $0.036 \mathrm{~s}$.

Inversion of P-wave automatic pickings from both the DAS and nodal arrays reports a similar epicentral region. These solutions, however, are clipped at the surface, as a consequence of two separate facts. The first is that the automatic pickings at both DAS and nodal arrays include slower arrivals from more distant stations, which had been discarded from the manual estimates (see Fig. 11d). In addition, the manual location takes advantage of S-wave arrival times, which provide a solid constraint on ray length and hence source depth.

Additional examples of locations derived from inversion of automatic first-arrival time pickings at the DAS virtual array are reported in the Supplement for events either cata- 


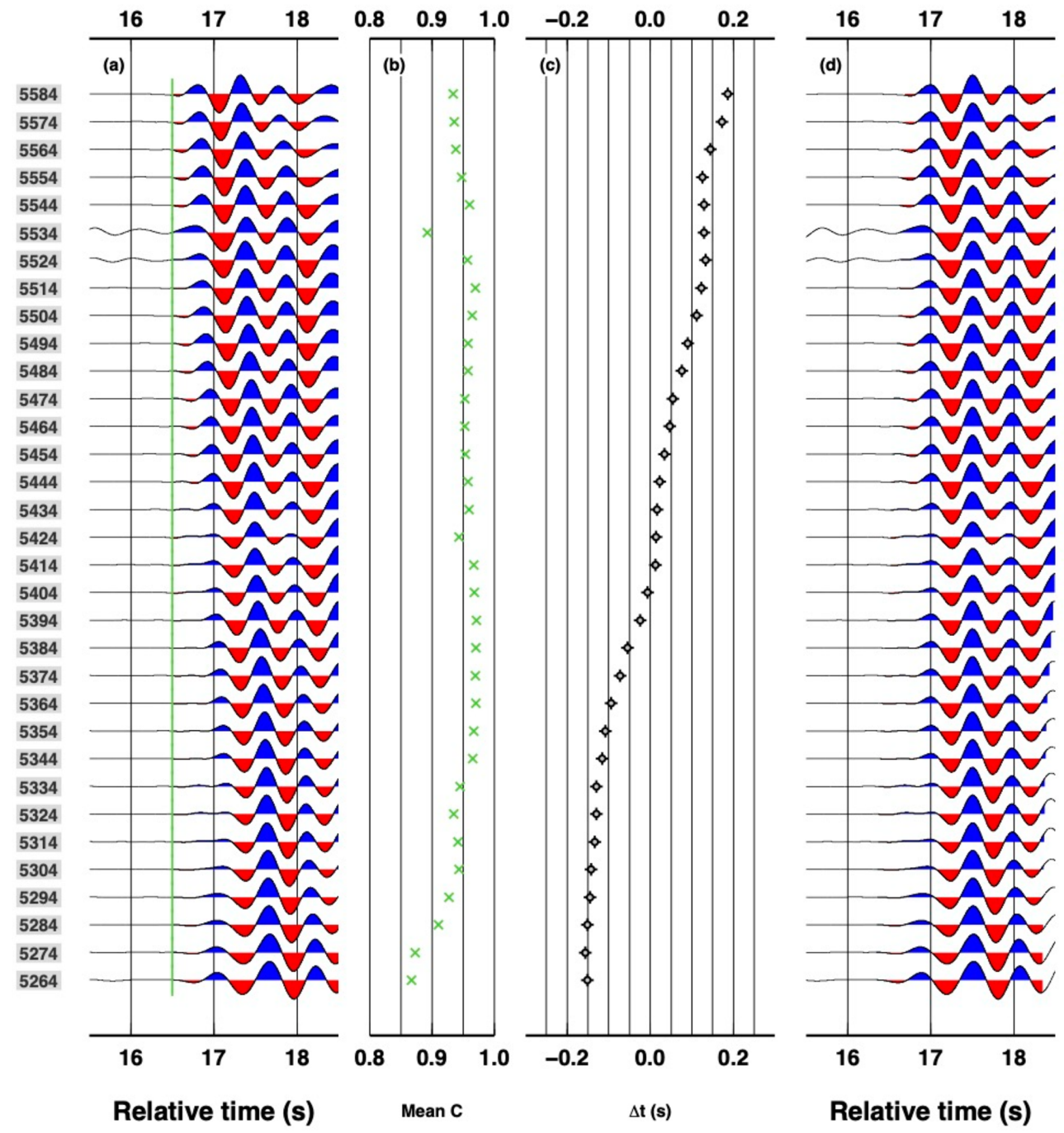

Figure 6. Example of analysis for computing P-wave time delays using VanDecar and Crosson (1990)'s approach applied to DAS channels along segment 48. Same panels as in Fig. 4.

logued by UC Berkeley Seismological Laboratory (2014) or reported in the list of template-matching detections from $\mathrm{Li}$ and Zhan (2018). In all these experiments, the performance of the DAS data to retrieve the "correct" location is comparable to that exhibited by the nodal deployment. However, a more comprehensive assessment of these results is made difficult by the fact that all the sources are located well outside of the deployments. Under such condition, and in absence of S-wave time pickings, the ability to retrieve the sourceto-receiver distance depends on the gradient of the velocity structure, which controls the geometry of the rays and hence their intersection with the surface.

\subsubsection{The Hawthorne earthquake}

In addition to what was described in the previous section, the DAS recordings from the Hawthorne earthquake have already been analysed in Wang et al. (2018) and van den Ende and Ampuero (2021). In particular, this latter study compared the performance of the DAS and nodal arrays in seismic beam forming for deriving the propagation parameters (apparent velocity and propagation azimuth) for the direct $\mathrm{P}$ - and S-wave arrivals. In their work, van den Ende and Ampuero (2021) applied the MUSIC method (Goldstein and Archuleta, 1991) to different combination of DAS channels; in no case, however, did they obtain results compatible with those expected for a single plane wave propagating along the source-to-receiver direction. This occurrence was attributed to marked velocity heterogeneities and scattering sources, locally distorting the wavefront and producing loss of signal coherence, in turn masking the weaker P-wave signal impinging at the array with steep incidence angles. Following this observation, van den Ende and Ampuero (2021) concluded that "... the DAS array exhibits poor waveform coher- 

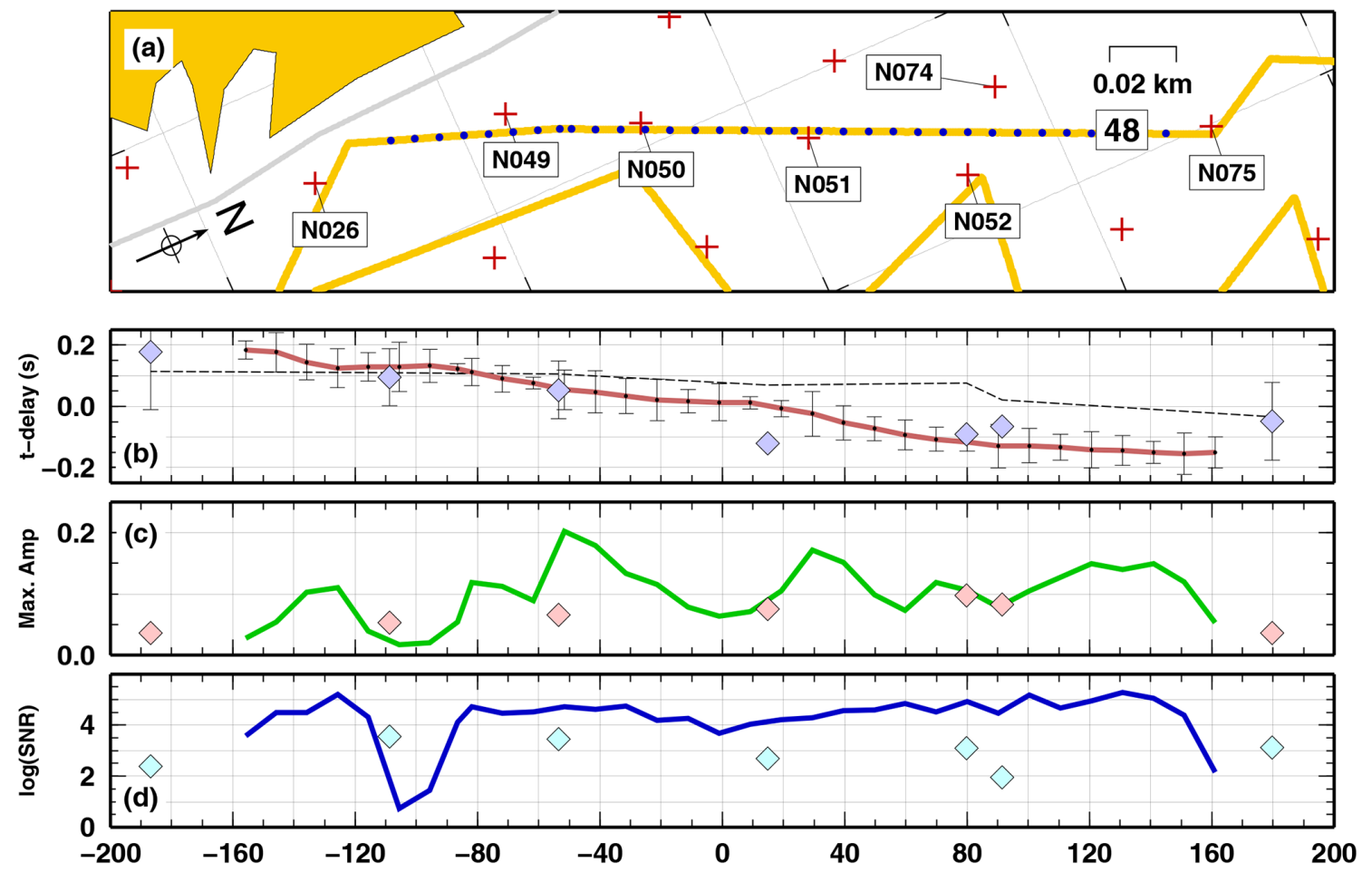

Distance along the segment (from the mid-point, meters)

Figure 7. Measurements along the single DAS segment 48 (coloured lines), compared to measurements obtained using rotated horizontal recordings of co-located nodal stations (grey diamonds). (a) Map of the DAS segments. (b) P-wave time delays with associated uncertainties, together with the P-wave time delays measured on the vertical components of the nodes (thin dashed black line); (c) maximum amplitude; and (d) $\log (\mathrm{SNR})$ as a function of the distance along the cable segment.

ence and consequently produces inadequate beam-forming results that are dominated by the signatures of shallow scattered waves".

Although these conclusions are fully consistent with the complex wave propagation we outlined above, our application of the PWF approach over short time windows sliding along the subsampled DAS recordings yields promising results which concern the real-time detection of sources at regional distance (Fig. 12). As a matter of fact, the onset of the earthquake signal is marked by an abrupt increase of the average multi-channel correlation (Fig. 12b) which, in correspondence with the P-wave arrival, peaks at a value which is about 2 times larger than those associated with the preceding background noise. The P-wave propagation azimuth associated with the most-correlated arrivals is biased by some $30^{\circ}$ with respect to what is expected from the source location. The apparent velocities associated with the most-correlated portion of the P-wave arrival are consistent with those estimated by van den Ende and Ampuero (2021) using data from the nodal array. Similar consistency is observed for the $\mathrm{S}$-wave arrival, even if its onset is less clear due to contamination by the P-coda wave train.

Overall, the results from this exercise suggest that (i) when dealing with seismic wavelengths comparable to the DAS aperture, a simple threshold on the overall correlation of DAS channels may serve as an efficient operator for detecting the arrival of an earthquake signal; (ii) although with some bias, the estimate of the $\mathrm{P}$-wave direction of propagation and apparent velocity is reliable enough to obtain a preliminary estimate about the back azimuth to the source, and (iii) a severe correlation-based weighting scheme is required to emphasise the delay times retrieved from the most coherent channel pairs.

\section{Discussion}

Our analysis confirms that DAS recordings can be used as complementary or in substitution of standard geophones for both monitoring activities and exploration of the subsurface. Taking into account the limitations of DAS recordings, several challenges should be addressed in the future for enabling the use of such data in, e.g. standard monitoring routines. Those challenges arise mainly from the intrinsically different structure of the data obtained from the fibre cable with respect to what is recorded from a set of single-vertical or 3C geophones, more than from the two different physical observables recorded by DAS and geophones. DAS data struc- 

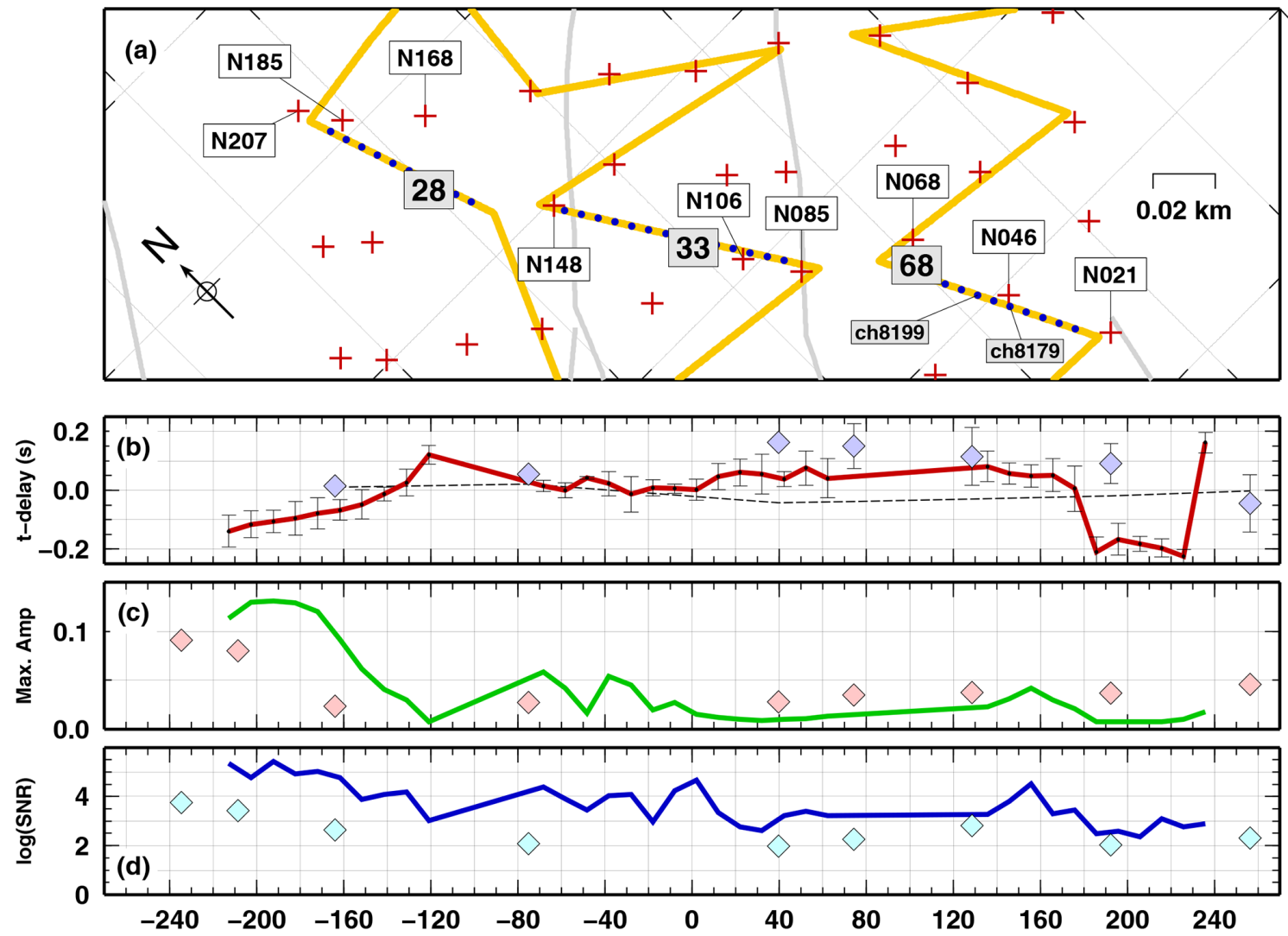

Distance along the segment (from the mid-point, meters)
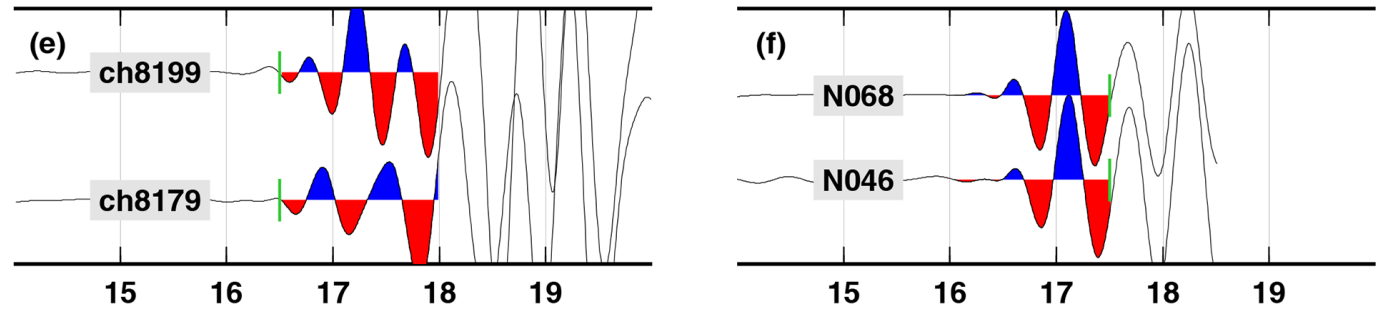

Relative time (s)

Figure 8. Same as Fig. 7 but for three consecutive (almost parallel) DAS segments: 68, 33 and 28. (e-f) Examples of waveforms recorded at DAS (e) and nodes (f).

ture is characterised by a huge amount of observations of the seismic waves along (1) a horizontal axis and (2) with a relatively poor areal coverage with respect to a standard seismic network. Exploiting such data structure would probably require to rethink the "old-style" algorithms used seismic data analysis, which have been developed since the 1970s mostly for areal distributions of individual vertical geophones. New approaches developed for large $\mathrm{N}$ deployment of geophones (e.g. Long Beach) could be more appropriate and easy to adapt to DAS data.

Our analysis of the DAS and geophone data substantiates previous findings that horizontal and vertical recordings gives different images of the propagation of distant events across a seismic array. This is a fundamental point to be kept in mind when analysing DAS data, which are only horizontal, in the most-used, standard configuration of the fibre cable. Local scattering phenomena associated with topographic roughness and/or velocity heterogeneities may negatively interfere with the propagation of the $\mathrm{P}$ wave, potentially overwhelming the first arrivals and biassing the measure of, e.g. relative time delays.

Looking into the details of the propagation of the $\mathrm{P}$ wave of a regional event along segments of fibre cable, we observe that local variations of standard measures (time delays, 


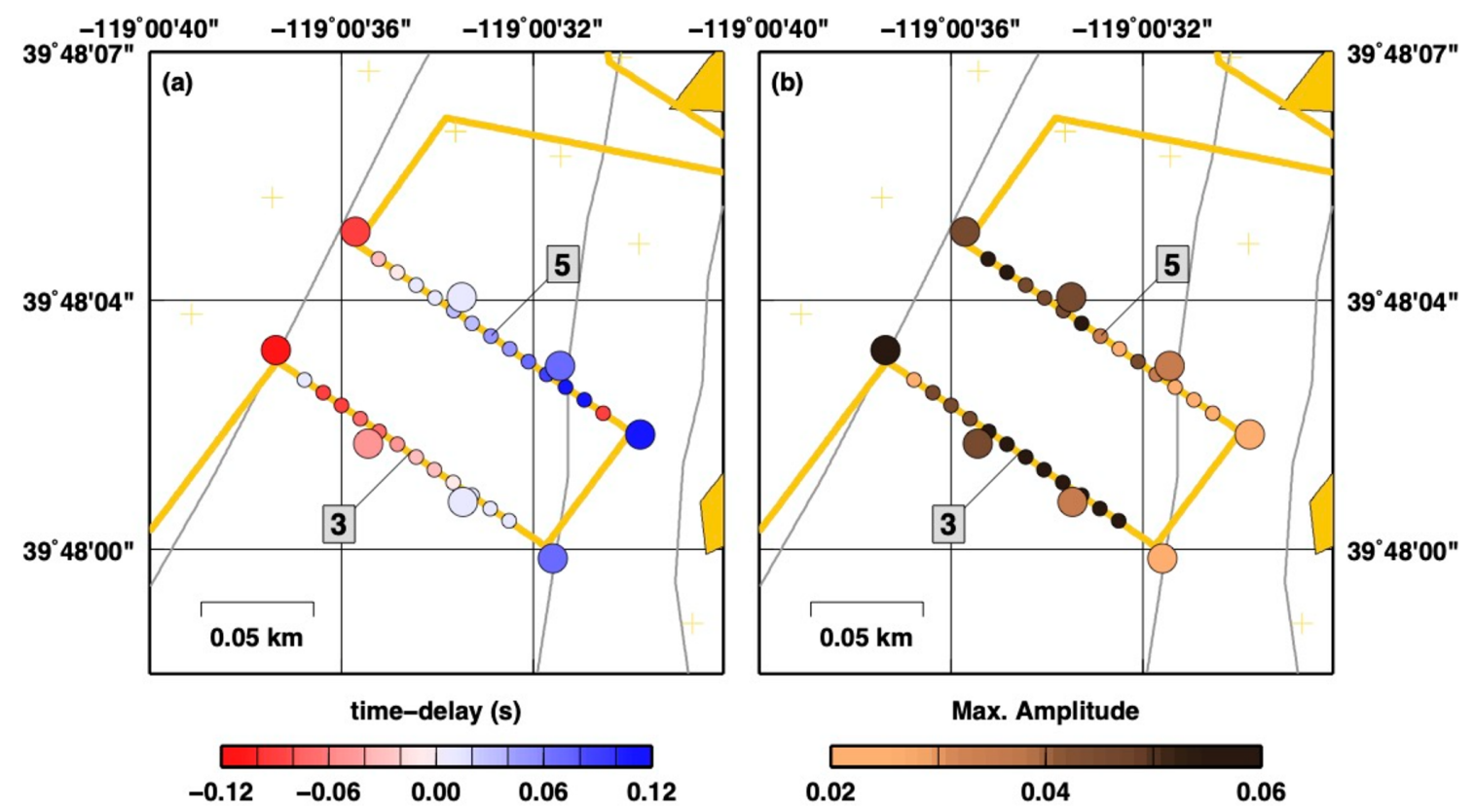

Figure 9. Map of: (a) P-wave time delays and (b) maximum amplitude for two parallel DAS segments: 3 and 5 (small coloured circles). Results for co-located nodal stations are also presented (large coloured circles).

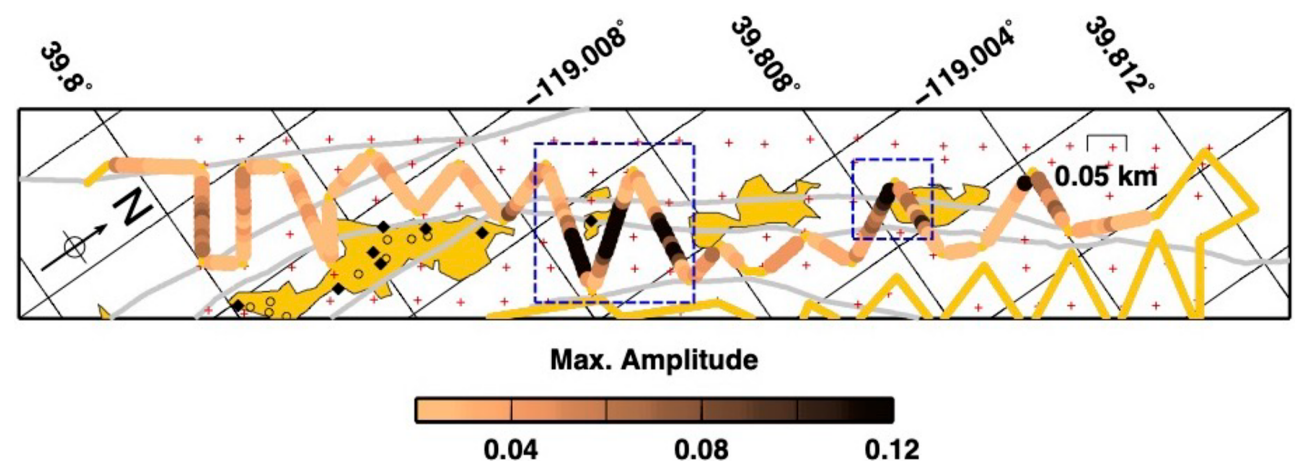

Figure 10. Amplitude analysis for all DAS segments along the northwestern side of the PoroTomo experiment (segments from 1 to 30 ). The dashed box indicates the area of maximum amplitude, which corresponds to the fibre cable crossing the warm ground and the area of the fumaroles/mud volcanoes.

SNR and maximum amplitude of the signal) are consistent between fibre cable and co-located geophones. In particular, we found that the analysis of the data recorded by a single segment of fibre cable shows the most stable results, even in the event of poor coupling of the fibre. Analysing the data for multiple, parallel, non-consecutive segments provides unclear results, likely as a consequence of scattering and wavefront distortion induced by local velocity heterogeneities. In this case, for the two parallel not-aligned segments, results are definitely promising, with potential for 3-D subsurface reconstructions. In the case of a profile composed of three separated segments, results are ambiguous and need further investigations. Analysing each single segment on the northwest side of the PoroTomo experiment where the geothermal phenomena are found (warm grounds and fumaroles), we show a potential correlation, at a higher resolution with respect to geophones, between amplitude variations of the recorded signal and local near-surface geology. However, such a correlation should be more quantitatively investigated with integrating a larger amount of geological data, which are not available to us at the moment, and needs further investigations to be confirmed.

In our experiments for the automatic location of local earthquakes, a basic autopicking procedure produces similar results once applied to the nodal and DAS data. In general, those time estimates require a preliminary selection before being used for locating seismic events. Moreover, in DAS data, seismic phase recognition can be more difficult than in geophone data, due to the absence of vertical recordings which are most sensitive to the P-wave arrival. Con- 
(a)
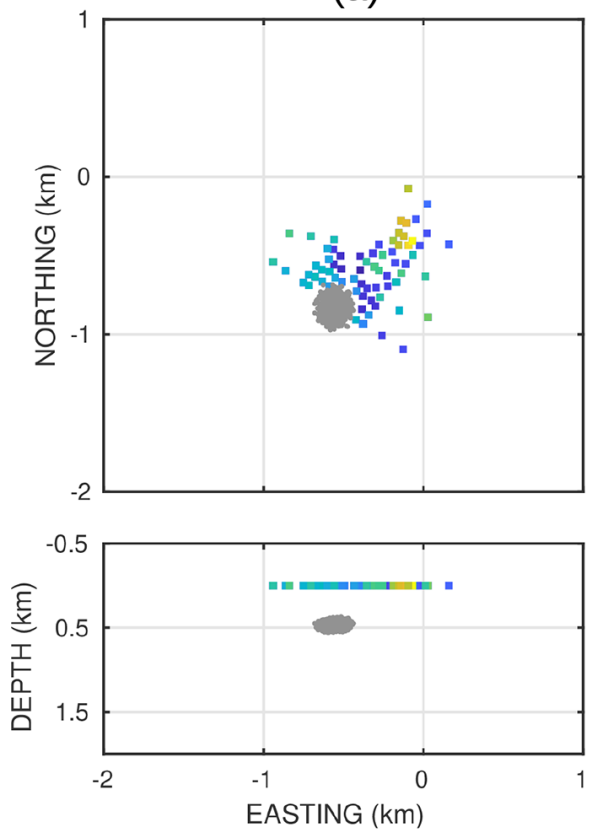

(c)
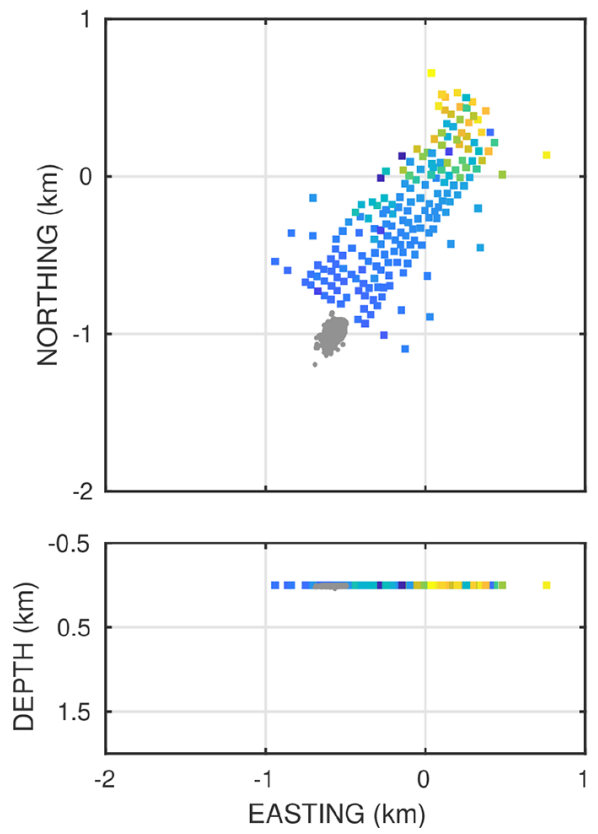

(b)
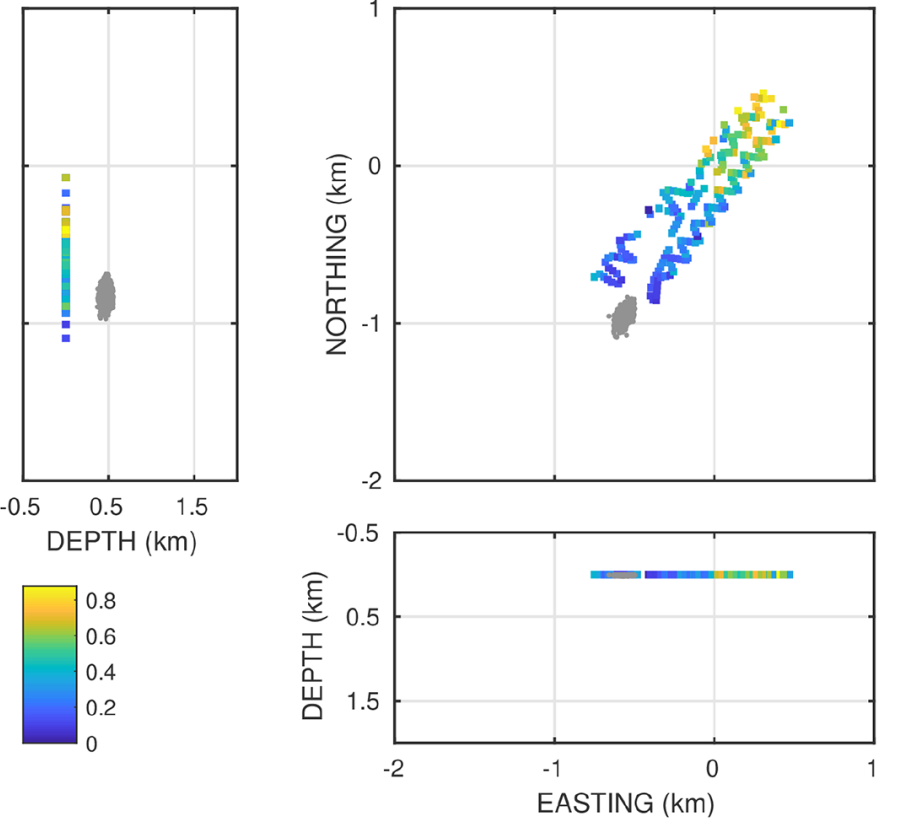

(d)
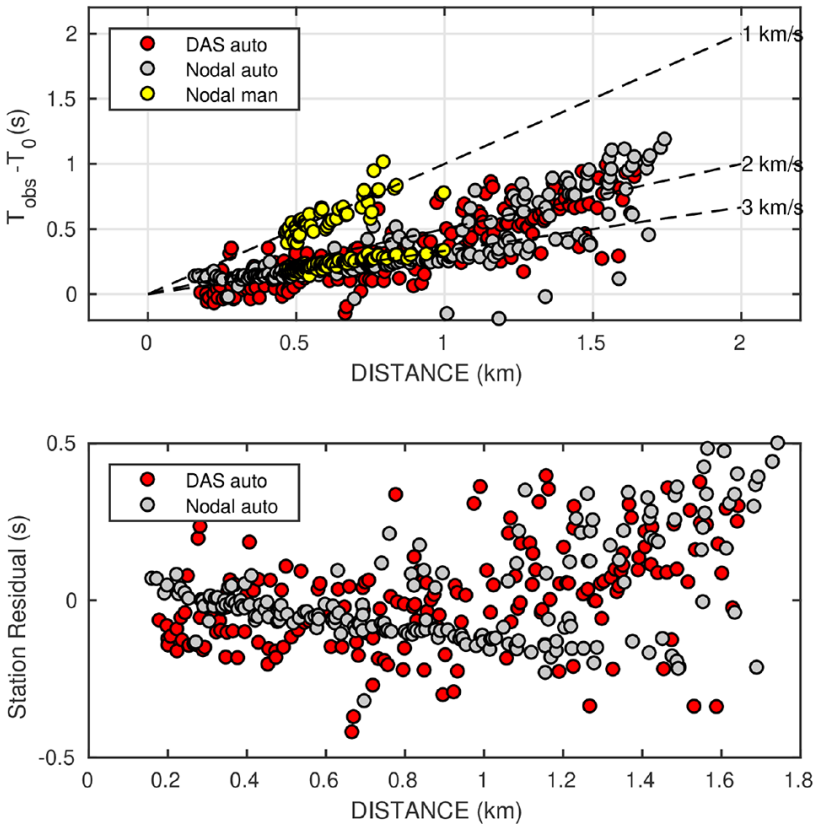

Figure 11. Author change: source location of the earthquake recorded on 14 March 2016 at 10:42:07 UTC. (a) Samples of the likelihood function of source location (grey dots) in map view and projected along two vertical sections oriented EW and NS. Results are from traveltime inversion of manually picked $\mathrm{P}$ - and S-wave arrivals at the nodal array. Colours indicate the timing of the picked arrivals, according to the colour scale at the bottom right. (b) The same as panel (a) but for the automatic picking obtained at the DAS virtual array. The likelihood function for source location is clipped at the surface grid boundary. (c) The same as panels (a) and (b) but from inversion of automatically picked P-wave first arrivals at the nodal array. (d) Arrival times derived at the DAS and nodal arrays as a function of epicentral distance. Dashed lines indicate the move-out corresponding to velocities spanning the $2-4 \mathrm{~km} \mathrm{~s}^{-1}$ interval. 

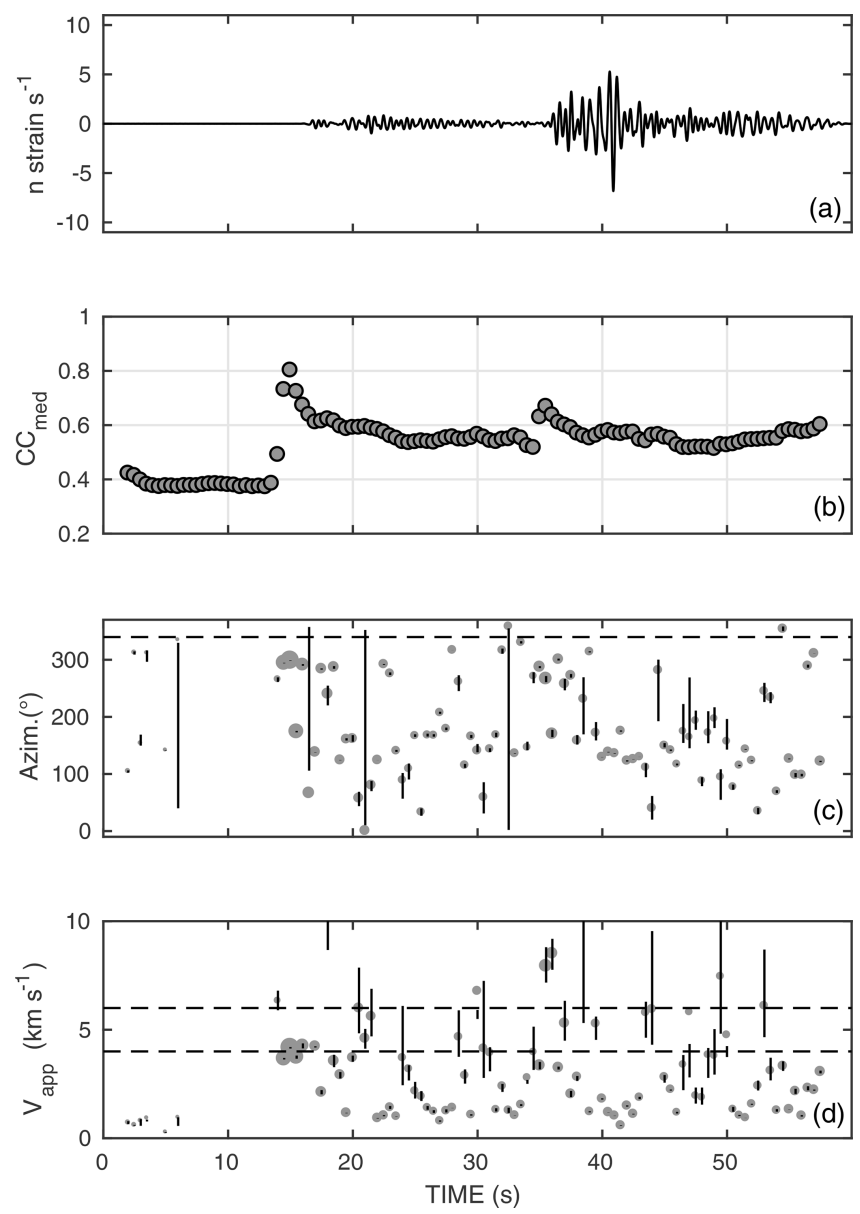

Figure 12. Results from fitting a plane wave to DAS differential times. (a) Recording of the Hawthorne earthquake from a sample DAS stacked channel. Data are band-pass filtered over the $0.5-2 \mathrm{~Hz}$ frequency band. (b) Mean of $C_{i j}^{\max }$ from all independent channels of the DAS stacked channels. (c) Propagation azimuth; the size of the points is proportional to the average correlation of the channels used for the inversion. The dashed line indicates the theoretical propagation azimuth ( $337^{\circ}$ clockwise from the $\mathrm{N}$ direction). (d) Apparent velocity, derived from the inverse of the modulus of the horizontal slowness vector. The dashed lines mark the velocity range obtained by van den Ende and Ampuero (2021) from the analysis of the nodal array data. Vertical bars indicate $2 \sigma$ uncertainties in azimuth and velocity.

verted/scattered waves from the P-wave coda can be easily incorrectly picked as $\mathrm{P}$ waves at more distant or less favourably oriented segments, where the background noise can mask the very first onset of longitudinal waves impinging at steep incidence angles. This is clearly observed in Fig. 11d: although the DAS pickings are generally consistent with the nodal ones, at short epicentral ranges, the former exhibit a larger scatter of the residuals, likely derived from misdetection of P-coda waves or even $\mathrm{S}$ waves.

DAS data analysis must thus rely on specific methodologies where the consistency of the data with the underly- ing hypothesis is statistically evaluated and accounted for. Within this context, it is worth mentioning a statistical approach developed recently, which consistently defines, in a Bayesian sense, the "membership" of each datum to the "outliers" class and which could help further developments of DAS data treatment (Tilmann et al., 2020).

In the case of wavelengths comparable to the size of the deployment, PWF results from the regional earthquake suggest that reliable event detection and location may be achieved. To that purpose, we deem that the most crucial aspect relies on the severe correlation-based channel selection and weighting scheme adopted in the inversion of differential times. While considering DAS potentialities for wave-field decomposition, we also note that the huge amount of available channels in DAS systems is perfectly suited for application of processing techniques that improve both accuracy and precision of existing frequency-wavenumber methods, such as sub-array spatial averaging (e.g. Goldstein and Archuleta, 1991).

Finally, we voluntarily skip an important task in seismic monitoring systems: the definition of the event magnitude. We are aware that such a task would require additional work to be fulfilled; as previously shown, DAS recordings may exhibit large-amplitude variations even at close-by channels, thus limiting the potential of using this kind of data for magnitude estimations. Nonetheless, recent studies (e.g. Lior et al., 2021) report promising indications toward utilisation of DAS data for source studies and magnitude evaluation.

\section{Conclusions}

We make use of DAS recordings obtained during PoroTomo experiment (Brady geothermal field) for testing their potential in simple subsurface mapping and monitoring tasks. We analyse waveforms from a regional events to get insights into the local structure of the geothermal field and from a local microseismic event to perform precise automatic event location. Our main findings are as follows:

1. DAS recordings can be used for monitoring and subsurface mapping purposes and their performance is comparable to seismological records. For the detection and location tasks, we confirm that pre-processing procedures, such as channel selection based on ground coupling, removal of channels close to cable corners, P- and $S$-phase identification and band-pass filtering tailored to the wavelength of interest, could be necessary to keep in the process data that satisfy quality requirements.

2. In addition to quality requirements, data selection is definitely necessary due to the large amount of data in DAS recordings. Taken together with the above point, this fact opens additional questions on the criteria to be followed for data selection and/or spatial/temporal 
subsampling, a sensitive point for developing automatic data-processing procedures.

3. DAS recordings represent horizontal ground displacement only, which limits, in some sense, the use of standard seismological analysis tools depicted specifically for the processing of vertical or 3-D ground motion. Within this context, a clear example is offered by the autopicking performances discussed in Sect. 3.2.1 and Sects. A1-A2 in the Appendix.

4. Although advantages and limitations of DAS systems as a seismic antenna need further investigation (van den Ende and Ampuero, 2021), our results indicate a clear potential of DAS toward coherence-based detection of sources at regional distance, complementing the results in Li and Zhan (2018) concerning detection of local microseismicity at low SNR. If used as a seismic antenna, DAS should be deployed according to multiple segments oriented along a large variety of azimuths, so as to increase the overall sensitivity toward distinct wave-type propagation along different directions.

New monitoring and subsurface mapping tools developed for DAS recordings are needed. In particular, exploration of the DAS data space (Tarantola, 2005; Piana Agostinetti and Sgattoni, 2021) would give an important contribution toward the analysis of DAS recording in a semi-automatic system.

\section{Appendix A: P-wave time delays from local event}

Here, we present the analysis of P-wave delay times for a local event. This analysis is complementary to the results presented in Sect. 3.1 because the frequency content of the $\mathrm{P}$-wave of a local event is generally between 10 and $20 \mathrm{~Hz}$. However, due to the close proximity of the event to the stations, we cannot consider a plane-wave approximation and we have to compute P-wave delay times using a different approach with respect to the analysis reported in Sect. 3.1. In Fig. A1, we show the geometry of the event, nodal stations and DAS channels along segment 48 . We make use of an event and cable geometry to try to maximise the P-wave delay times along the cable; i.e. the event occurs almost along the segment strike. Recordings of the local events for three systems are considered: vertical nodal stations, oriented horizontal nodal stations and DAS channels. The three systems have been analysed with the same workflow which encompasses both (1) automatic picking of a P-wave based on classical autopicker (Baer and Kradolfer, 1987) and (2) manual revision of the automatic pickings. The Baer picker has been developed as a ObsPy package, and we set it with its default values (Beyreuther et al., 2010).

A P wave on the vertical component of the nodal stations displays a high SNR and can be easily detected by the automatic picker (vertical violet bars in Fig. A2a, not

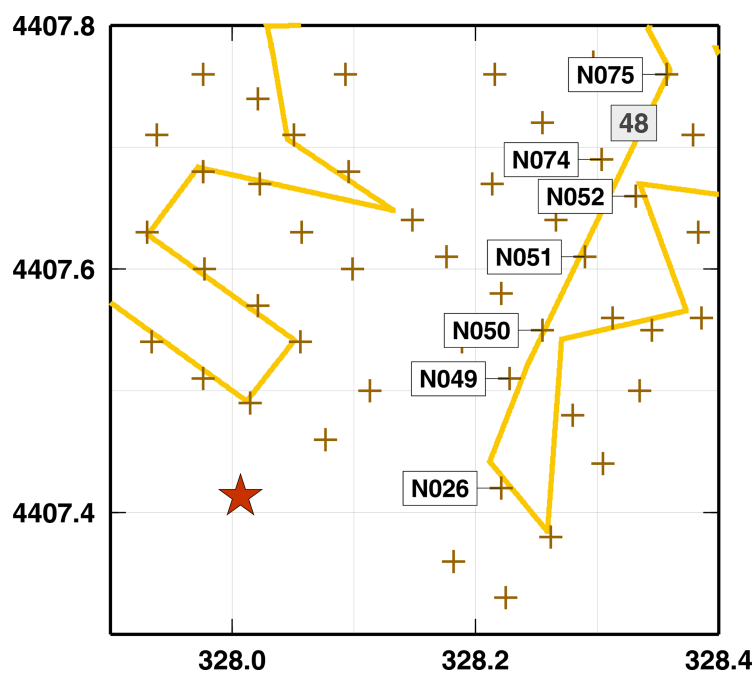

Figure A1. Map of the event, nodes and DAS segment used for retrieving P-wave delay times in the case of a local microseism. Crosses and yellow lines indicate the nodes and the DAS cable, respectively. Investigated nodes and DAS segment are labelled. A red star displays the event epicentre, as located using the geophone data and manual picking of $\mathrm{P}$ and $\mathrm{S}$ phases.

really visible because they are below the green bars). One station (N051) has a more limited SNR and identifying Pwave arrival can be more challenging. Manual revision does not sensibly change the arrival times (vertical green bars in Fig. A2a). Conversely, the P wave on the oriented horizontal components of the nodal stations displays a smaller SNR, at least for some stations (vertical violet bars in Fig. A2b), which need substantial manual revision, at least for N051. Autopicker results and manual revision on DAS channels are more interesting. The $\mathrm{P}$-wave arrival times obtained with the Baer picker (vertical violet bars in Fig. A2c) display a coherent pattern from channels 5579 to 5419 , the closest half of the segment to the epicentre. In the second half of the segment, the autopicker gives more scattered results. Compared with the manual pickings (vertical green bars in Fig. A2c), which also have a larger variability in the second half with respect to the first half, such automatic pickings seem, in many cases, to arise from the misdetection of either a receiver-side converted wave, $\mathrm{P}_{\mathrm{s}}$ or $\mathrm{S}_{\mathrm{p}}$, or the $\mathrm{S}$ wave itself, as a $\mathrm{P}$ wave.

Manual pickings in the three systems are presented in Fig. A2d). Manual pickings for both horizontal and vertical components of the nodal stations (grey symbols) are generally similar, with slightly higher delay times for the horizontal components. Notably, those delay times coincide with the delay times measured along the cable approximately in the same locations (some nodal station have been deployed not exactly on the fibre cable). Delay times measured along with the DAS show a more complex pattern with coherently higher values in some sections of the cable (e.g. between channels 5389 and 5359). This analysis confirms the poten- 
tial for the DAS recordings to reach a higher resolution especially if gauge length can be reduced to $1 \mathrm{~m}$, which is already feasible with the next generation of fibre interrogators. However, also in this case, picking procedures, established for a network of vertical components, do not perform with profit, when applied to horizontal recordings.

(a) Z NODAL

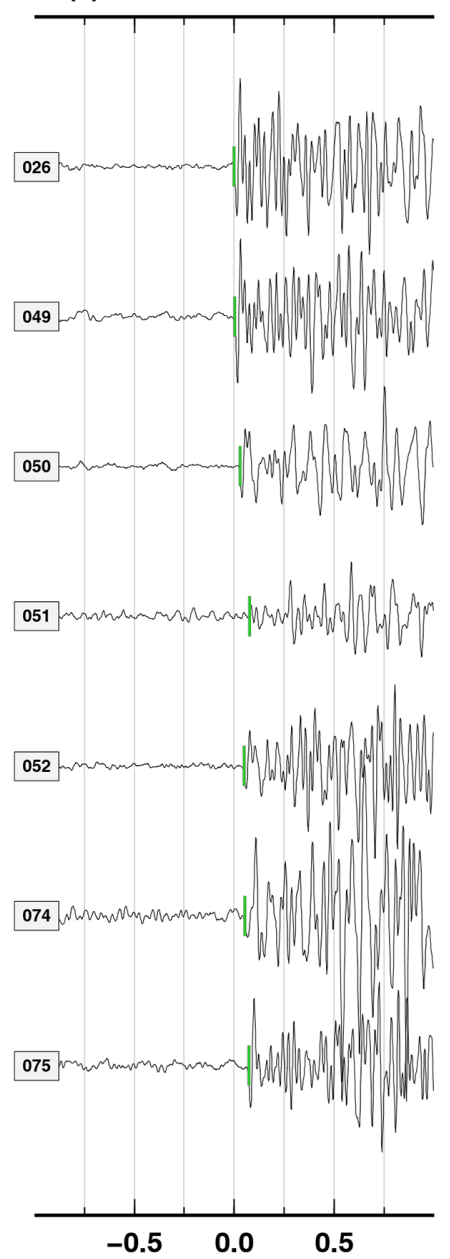

(b) H NODAL

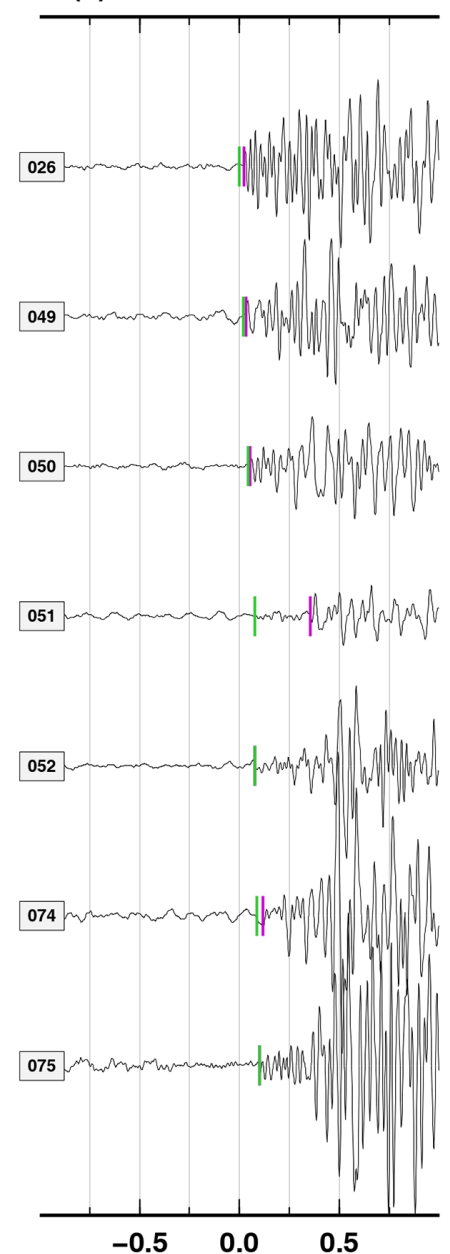

(c) DAS CHANNELS

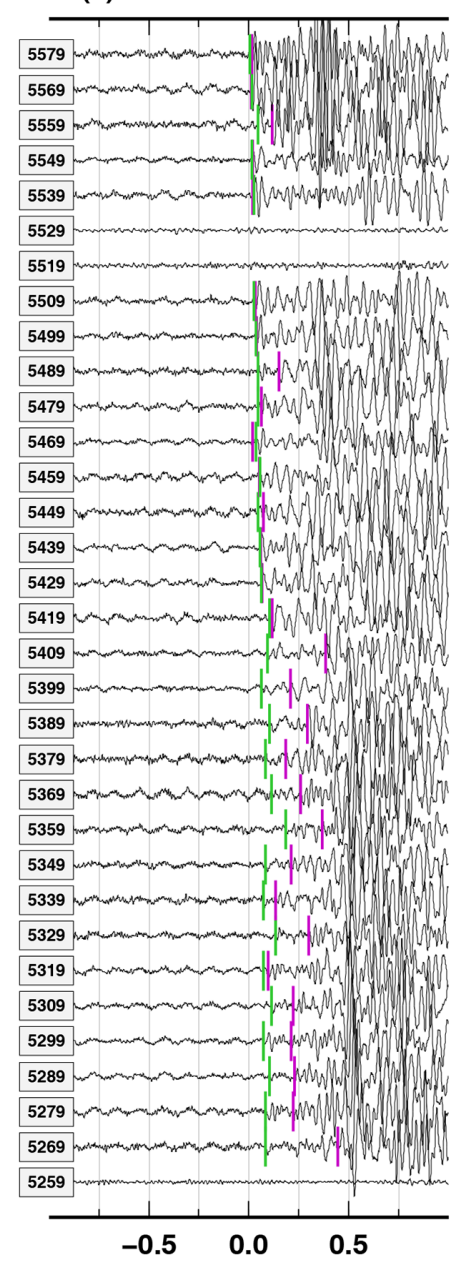

Time from first P-pick (s)

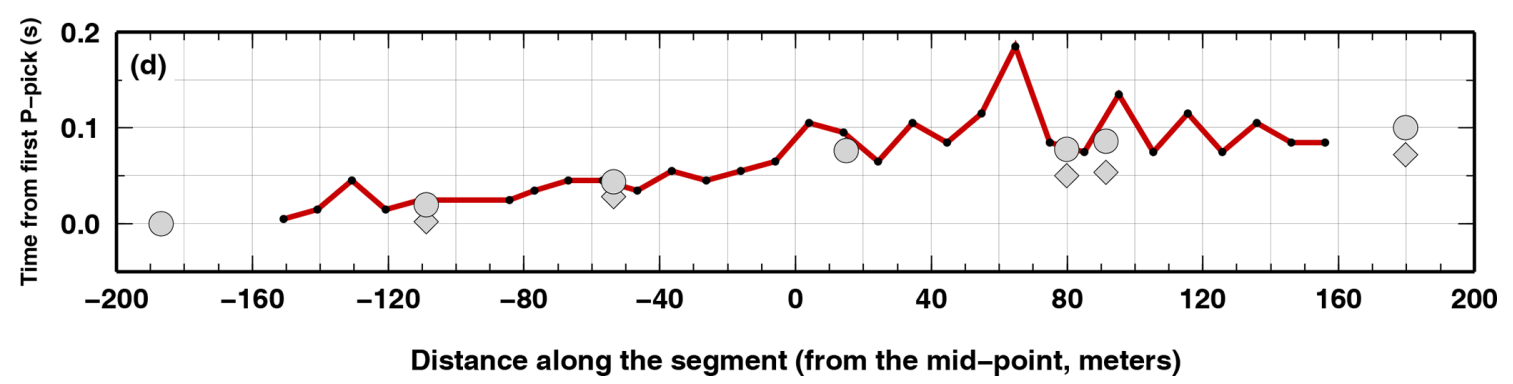

Figure A2. (a) Vertical recordings of the geophones along the DAS segment 48. Vertical green and violet bars indicate manual and automatic picking of $\mathrm{P}$ waves. Panel (b) is the same as (a) but for the oriented horizontal component. (c) DAS recordings along segment 48. Symbols are as in panel (a). (d) Relative P-wave delay times from the first P pick for the three sets of waves displayed in (a) grey diamonds, (b) grey circles and (c) a red line and black dots. 
Appendix B: Amplitude variations with frequency: the case study of Vibroseis recordings

To obtain more insights regarding the amplitude of the signal recorded along the fibre cable, we analyse the signal generated by a Vibroseis truck in a position along the strike of segment 48. The T49 Vibroseis sweeps considered here are three sweeps generated in the same location with the same apparatus (P source). Thus, for each geophone and each DAS channel, we obtain an averaged value for the maximum amplitude of the filtered signals and a standard deviation. The Vibroseis sweeps consist in a $20 \mathrm{~s}$ signal of increasing frequency, from 5 to $80 \mathrm{~Hz}$. Here, we selected three frequency bands (5-10, 10-20 and 20-40 Hz) and we measured the maximum amplitude of the filtered signal as it varies along the cable. In this way, we can highlight local amplification for specific frequency bands.

In Fig. B1a), we show the geometry of the source and receivers. The source is indicated as T49. One station (N026) is clearly closer to the source with respect to the cable, and results from this station have been removed. Visual inspection of the three frequency bands (e.g. for one station and one colocated channel, Fig. B1b) shows that variations observed in the geophone recordings are also mapped in the DAS recordings. The patterns in maximum amplitude for the two systems (oriented horizontal geophones and DAS) as a function of the distance from T49 are shown in Fig. B1c. Such patterns are coherent in all the three frequency bands. In particular, for the $10-20 \mathrm{~Hz}$ band, local amplifications found in the geophone data are consistently retrieved from the DAS data (maximum amplitude found at about $x=210 \mathrm{~m}$ ). Moreover, DAS data offer high-resolution details clearly not available from the geophone data (due to their large inter-station distance). Our analysis confirms that DAS recordings can be used to obtain trustable information on the amplitude of the recorded signal. Again, the high spatial sampling of the fibre cable allows us to extract information unavailable using sparse stations. 


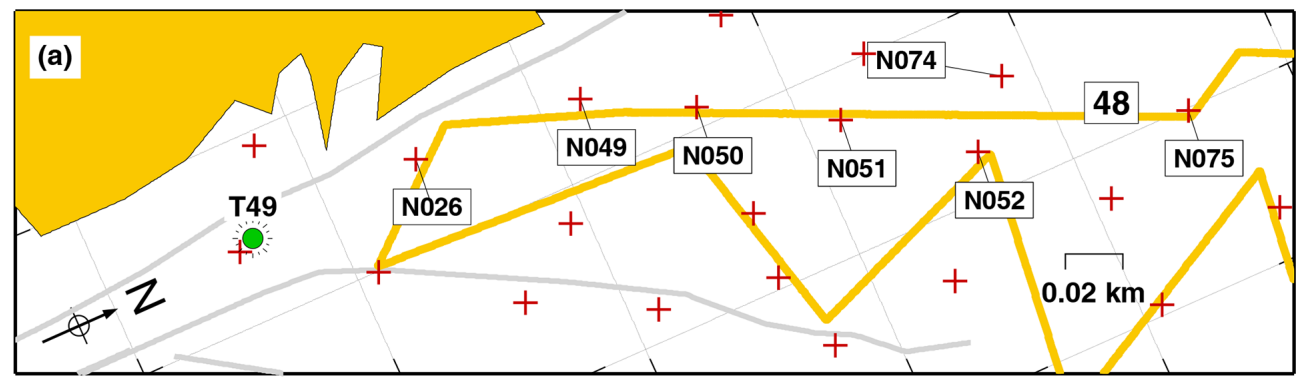

(b) Recordings of vibroseis sweep T49 at node: N050 (grey lines) and channel: $\mathbf{5 4 7 9}$ (red lines)
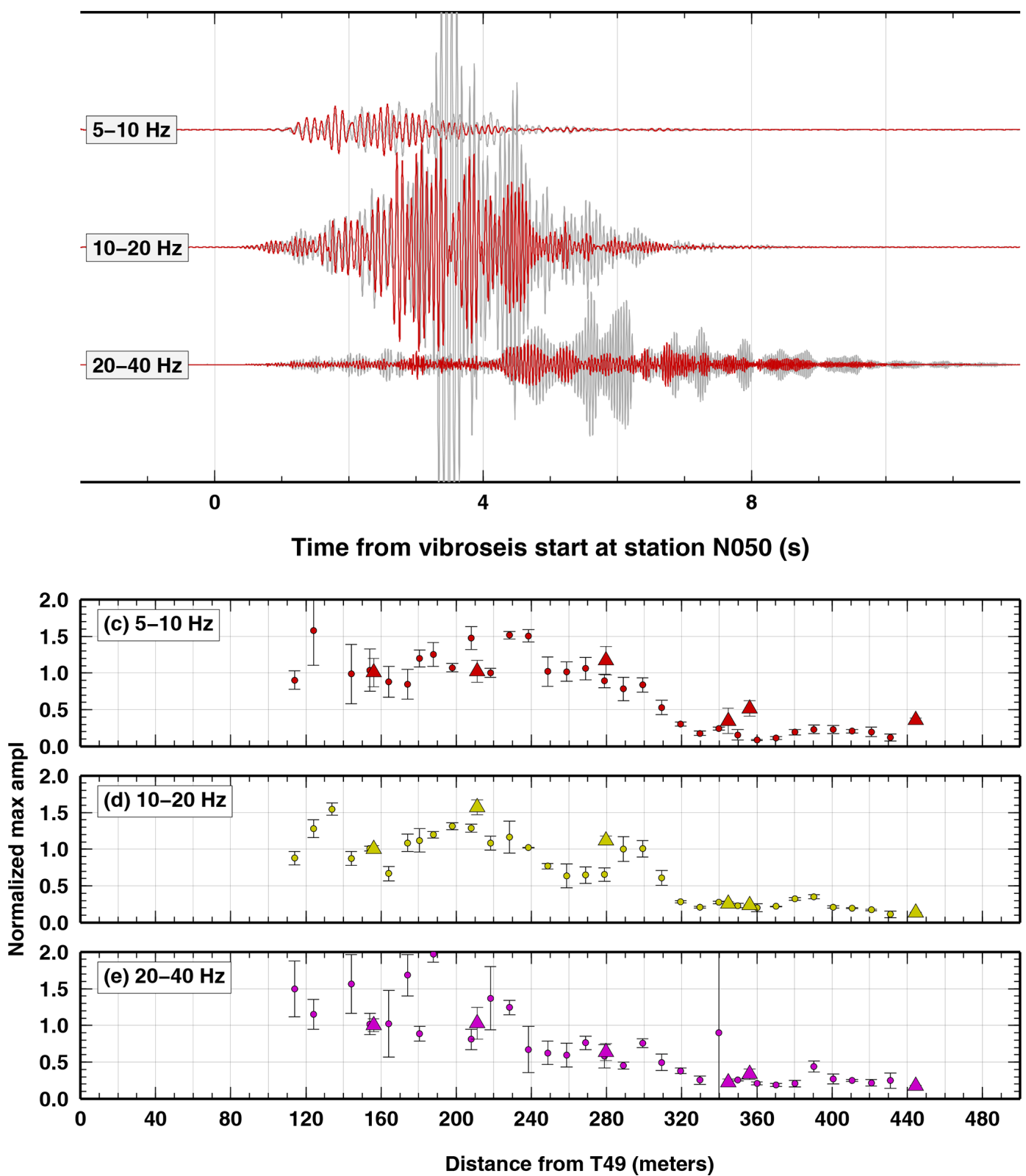

Figure B1. Analysis of the amplitude variations along DAS segment 48, from Vibroseis recordings. (a) Map of the Vibroseis source location (grey circle, labelled T49) nodes (labelled grey crosses) and DAS segment 48 (labelled yellow line). (b) Example of filtered recordings of a Vibroseis sweep at co-located node N050 and DAS channel 5479. Variations in maximum amplitude for the nodes (coloured triangles) and the DAS channels (coloured circles) in different frequency bands: (c) 5-10; (d) 10-20; and (e) 20-40 Hz. 
Code availability. Some figures are plotted using GMT (Wessel et al., 1998).

Data availability. PoroTomo data are available at https://doi.org/10.15121/1368198 (University of Wisconsin, 2016).

Supplement. The supplement related to this article is available online at: https://doi.org/10.5194/se-13-449-2022-supplement.

Author contributions. NPA and AV equally contributed to the data analysis in the subsurface mapping analysis. GS developed and executed the monitoring analysis. NPA and GS wrote the original draft of the manuscript.

Competing interests. The contact author has declared that neither they nor their co-authors have any competing interests.

Disclaimer. Publisher's note: Copernicus Publications remains neutral with regard to jurisdictional claims in published maps and institutional affiliations.

Special issue statement. This article is part of the special issue "Fibre-optic sensing in Earth sciences". It is not associated with a conference.

Acknowledgements. We kindly thank Martijn van den Ende, Herbert Wang and an anonymous reviewer for their constructive discussion about DAS data analysis and interpretation. Nicola Piana Agostinetti thanks PoroTomo team (Kurt Feigl, Nicole Taverna and Jon Weers) for their continuous support in handling the data.

Financial support. This research has been supported by the Austrian Science Fund (grant no. M2218-N29).

Review statement. This paper was edited by Philippe Jousset and reviewed by Martijn van den Ende, Herbert Wang, and one anonymous referee.

\section{References}

Ajo-Franklin, J. B., Doou, S., Lindsey, N. J., Monga, I., Tracy, C., Robertson, M., Rodriguez Tribaldos, V., Ulrich, C., Freifeld, B., Daley, T., and Li, X.: Distributed Acoustic Sensing Using Dark Fiber for Near-Surface Characterization and Broadband Seismic Event Detection, Sci. Rep., 9, 1328, https://doi.org/10.1038/s41598-018-36675-8, 2019.
Ali, S., Akerley, J., Baluyut, E., Cardiff, M., Davatzes, N., Feigl, K., Foxall, W., Fratta, D., Mellors, R., Spielman, P., Wang, H., and Zemach, E.: Time-series analysis of surface deformation at Brady Hot Springs geothermal field (Nevada) using interferometric synthetic aperture radar, Geothermics, 61, 114-120, https://doi.org/10.1016/j.geothermics.2016.01.008, 2016.

Baer, M. and Kradolfer, U.: An automatic phase picker for local and teleseismic events, B. Seismol. Soc. Am., 77, 1437-1445, https://doi.org/10.1785/BSSA0770041437, 1987.

Beyreuther, M., Barsch, R., Krischer, L., Megies, T., Behr, Y., and Wassermann, J.: ObsPy: A Python Toolbox for Seismology, Seismol. Res. Lett., 81, 530-533, https://doi.org/10.1785/gssrl.81.3.530, 2010.

Cardiff, M., Lim, D. D., Patterson, J. R., Akerley, J., Spielman, P., Lopeman, J., Walsh, P., Singh, A., Foxall, W., Wang, H. F., Lord, N. E., Thurber, C. H., Fratta, D., Mellors, R. J., Davatzes, N. C., and Feigl, K. L.: Geothermal production and reduced seismicity: Correlation and proposed mechanism, Earth Planet. Sc. Lett., 482, 470-477, https://doi.org/10.1016/j.epsl.2017.11.037, 2018.

Del Pezzo, E. and Giudicepietro, F.: Plane Wave Fitting Method for a Plane, Small Aperture, Short Period Seismic Array: A MATHCAD Program, Comput. Geosci., 28, 59-64, https://doi.org/10.1016/S0098-3004(01)00076-0, 2002.

Ester, M., Kriegel, H.-P., Sander, J., Xu, X., et al.: A density-based algorithm for discovering clusters in large spatial databases with noise, in: Kdd, Vol. 96, 226-231, 1996.

Faulds, J. E., Coolbaugh, M., Vice, G. S., and Edwards., M. L.: Characterizing Structural Controls of Geothermal Fields in the Northwestern Great Basin - A Progress Repor, in: Transactions GRC Annual Meeting, Geoth. Res. T., 69-76, 2006.

Feigl, K. L. and Parker, L. M.: PoroTomo Final Technical Report: Poroelastic Tomography by Adjoint Inverse Modeling of Data from Seismology, Geodesy, and Hydrology, Tech. rep., Univ. of Wisconsin, Madison, WI, USA, 176 pp., https://doi.org/10.2172/1499141, 2019.

Feigl, K. and The PoroTomo Team: Overview and Preliminary Results from the PoroTomo project at Brady Hot Springs, Nevada: Poroelastic Tomography by Adjoint Inverse Modeling of Data from Seismology, Geodesy, and Hydrology, in: 42nd Workshop on Geothermal Reservoir Engineering, Stanford University, 2017.

Feigl, K. L. and POROTOMO team: Retrieved from https://doi.org/10.15121/1721671, 2016.

Goldstein, P. and Archuleta, R. J.: Deterministic frequencywavenumber methods and direct measurements of rupture propagation during earthquakes using a dense array: Theory and methods, J. Geophys. Res.-Sol. Ea., 96, 6173-6185, https://doi.org/10.1029/90JB02123, 1991.

Henninges, J., Martuganova, E., Stiller, M., Norden, B., and Krawczyk, C. M.: Wireline distributed acoustic sensing allows $4.2 \mathrm{~km}$ deep vertical seismic profiling of the Rotliegend $150^{\circ} \mathrm{C}$ geothermal reservoir in the North German Basin, Solid Earth, 12, 521-537, https://doi.org/10.5194/se-12-521-2021, 2021.

Jolie, E., Moeck, I., and Faulds, J. E.: Quantitative structuralgeological exploration of fault-controlled geothermal systems - A case study from the Basin-and-Range Province, Nevada (USA), Geothermics, 54, 54-67, https://doi.org/10.1016/j.geothermics.2014.10.003, 2015. 
Jousset, P., Reinsch, T., Ryberg, T., Blanck, H., Clarke, A., Aghayev, R., Hersir, G. P., Henniges, J., Weber, M., and Krawczyk, C.: Dynamic strain determination using fibre-optic cables allows imaging of seismological and structural features, Nat. Commun., 9, 2509, https://doi.org/10.1038/s41467-01804860-y, 2018.

Jreij, S. F., Trainor-Guitton, W., Morphew, M. D., and Ning, I. L. C.: The Value of Information From Horizontal Distributed Acoustic Sensing Compared to Multicomponent Geophones Via Machine Learning, Journal of Energy Resources Technology-transactions of The Asme, 143, https://doi.org/10.1115/1.4048051, 2021.

Langet, N., Maggi, A., Michelini, A., and Brenguier, F.: Continuous kurtosis-based migration for seismic event detection and location, with application to Piton de la Fournaise Volcano, La Reunion, Bull. Seismol. Soc. Am., 104, 229-246, 2014.

Li, Z. and Zhan, Z.: Pushing the limit of earthquake detection with distributed acoustic sensing and template matching: a case study at the Brady geothermal field, Geophys. J. Int., 215, 1583-1593, https://doi.org/10.1093/gji/ggy359, 2018.

Lindsey, N. J., Dawe, T. C., and Ajo-Franklin, J. B.: Illuminating seafloor faults and ocean dynamics with dark fiber distributed acoustic sensing, Science, 366, 1103-1107, https://doi.org/10.1126/science.aay5881, 2019.

Lior, I., Sladen, A., Mercerat, D., Ampuero, J.-P., Rivet, D., and Sambolian, S.: Strain to ground motion conversion of distributed acoustic sensing data for earthquake magnitude and stress drop determination, Solid Earth, 12, 1421-1442, https://doi.org/10.5194/se-12-1421-2021, 2021.

Lomax, A., Michelini, A., and Curtis, A.: Earthquake Location, Direct, Global-Search Methods, Springer New York, New York, NY, 2449-2473, https://doi.org/10.1007/978-0-38730440-3_150, 2009.

Parker, L. M., Thurber, C. H., Zeng, X., Li, P., Lord, N. E., Fratta, D., Wang, H. F., Robertson, M. C., Thomas, A. M., Karplus, M. S., Nayak, A., and Feigl, K. L.: Active source seismic tomography at the Brady geothermal field, Nevada, with dense nodal, Seismol. Res. Lett., 89, 1629-1640, https://doi.org/10.1785/0220180085, 2018.

Piana Agostinetti, N. and Martini, F.: Sedimentary basins investigation using teleseismic P-wave time delays, Geophys. Prospect., 67, 1676-1685, https://doi.org/10.1111/1365-2478.12747, 2019.

Piana Agostinetti, N. and Sgattoni, G.: Changepoint detection in seismic double-difference data: application of a transdimensional algorithm to data-space exploration, Solid Earth, 12, 2717-2733, https://doi.org/10.5194/se-12-2717-2021, 2021.

Shevenell, L. and De Rocher, T.: Evaluation of Chemical Geothermometers for Calculating Reservoir Temperatures at Nevada Geothermal Power Plants, in: Geothermal Resources Council Transactions, Vol. 29, 303-308, 2005.
Sladen, A., Rivet, D., Ampuero, J. P., Barros, L. D., Hello, Y., Calbris, G., and Lamare, P.: Distributed sensing of earthquakes and ocean-solid Earth interactions on seafloor telecom cables, Nat. Commun., 10, 5777, https://doi.org/10.1038/s41467-019-13793z, 2019.

Sleeman, R. and van Eck, T.: Robust automatic P-phase picking: an on-line implementation in the analysis of broadband seismogram record- ings, Phys. Earth Planet. Int., 113, 265-275, https://doi.org/10.1016/S0031-9201(99)00007-2, 1999.

Tarantola, A.: Inverse Problem Theory and Methods for Model Parameter Estimation, SIAM, https://epubs.siam.org/doi/book/10. 1137/1.9780898717921 (last access: 26 February 2022), 2005.

Tilmann, F. J., Sadeghisorkhani, H., and Mauerberger, A.: Another look at the treatment of data uncertainty in Markov chain Monte Carlo inversion and other probabilistic methods, Geophys. J. Int., 222, 388-405, https://doi.org/10.1093/gji/ggaa168, 2020.

UC Berkeley Seismological Laboratory: Northern California Earthquake Data Center, https://doi.org/10.7932/NCEDC, 2014.

University of Wisconsin: Brady's Geothermal Field - Map of DAS, Nodal, Vibroseis and Reftek Station Deployment [data set], https://doi.org/10.15121/1368198, 2016.

van den Ende, M. P. A. and Ampuero, J.-P.: Evaluating seismic beamforming capabilities of distributed acoustic sensing arrays, Solid Earth, 12, 915-934, https://doi.org/10.5194/se-12915-2021, 2021.

VanDecar, J. C. and Crosson, R. S.: Determination of teleseismic relative phase arrival times using multi-channel crosscorrelation and least squares, B. Seismol. Soc. Am., 80, 150-169, https://doi.org/10.1785/BSSA0800010150, 1990.

Wang, H. F., Zeng, X., Miller, D. E., Fratta, D., Feigl, K. L., Thurber, C. H., and Mellors, R. J.: Ground motion response to an ML 4.3 earthquake using co-located distributed acoustic sensing and seismometer arrays, Geophys. J. Int., 213, 2020-2036, https://doi.org/10.1093/gji/ggy 102, 2018.

Wessel, P., Smith, W. H. F., Scharroo, R., Luis, J., and Wobbe, F.: Generic Mapping Tools: Improved Version Released, Eos Trans. AGU, 94, 409, https://doi.org/10.1002/2013EO450001, 2013.

You, Y.: Harnessing telecoms cables for science, Nature, 466, 690691, 2010.

Yu, C., Zhan, Z., Lindsey, N. J., Ajo-Franklin, J. B., and Robertson, M.: The Potential of DAS in Teleseismic Studies: Insights From the Goldstone Experiment, Geophys. Res. Lett.s, 46, 1320-1328, https://doi.org/10.1029/2018GL081195, 2019.

Zeng, X., Lancelle, C., Thurber, C., Fratta, D., Wang, H., Chalari, A., and Clarke, A.: Properties of Noise Cross-Correlation Functions Obtained from a Distributed Acoustic Sensing Array at Garner Valley, California, B. Seismol. Soc. Am., 107, 603-610, https://doi.org/10.1785/0120160168, 2017. 